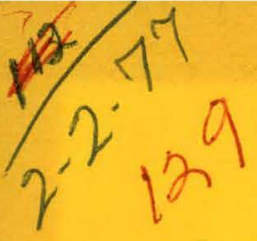

MLM-2384
Dr 654

MLM-2384

\title{
A Study of the Reaction of Uranium and Plutonium with Bone Char
}

Gary L. Silver and John W. Koenst

January 17, 1977

\section{MOUND LABORATORY}

Miamisburg, Ohio

operated by

Monsanto

MONSANTO RESEARCH CORPORATION a subsidiary of Monsanto Company for the UNITED STATES ENERGY RESEARCH AND DEVELOPMENT ADMINISTRATION U.S. Government Contract No. EY-76-C-04-0053 


\section{DISCLAIMER}

This report was prepared as an account of work sponsored by an agency of the United States Government. Neither the United States Government nor any agency Thereof, nor any of their employees, makes any warranty, express or implied, or assumes any legal liability or responsibility for the accuracy, completeness, or usefulness of any information, apparatus, product, or process disclosed, or represents that its use would not infringe privately owned rights. Reference herein to any specific commercial product, process, or service by trade name, trademark, manufacturer, or otherwise does not necessarily constitute or imply its endorsement, recommendation, or favoring by the United States Government or any agency thereof. The views and opinions of authors expressed herein do not necessarily state or reflect those of the United States Government or any agency thereof. 


\section{DISCLAIMER}

Portions of this document may be illegible in electronic image products. Images are produced from the best available original document. 


\section{NOTICE}

This report wes prepared as an eccount of work sponsored by the United States Government. Neither the United States nor the United States Energy Research and Development Administration, nor any of their employees, nor any of their contractors, subcontractors, or their employees, makes any warranty, express or implied, or assumes any legal liability or responsibility for the accuracy, com.

pleteness or usefulness of any information, apparatus, product or process disclosed or represents that its use would not infringe privately owned rights. 


\title{
A Study of the Reaction of Uranium and Plutonium with Bone Char
}

\author{
Gary L. Silver and John W. Koenst
}

Issued: January 17, 1977

PRINTED IN THE UNITED STATES OF AMERICA

Avallable from

Notional Technical Information Service

U.S. Department of Commerce

6285 Port Royal Road

Springfleld, Virginia 22161

Prioal Printed Gopy \$4.00; Microfiche $\$ 3$. nn

\section{MONSANTO RESEARCH CORPORATION}

A Subsidiary of Monsanto Company

\section{mOUnD IABORATORY}

Miamisburg; Ohio 45342

operated for.

\section{UNITED STATES ENERGY RESEARCH AND DEVELOPMENT ADMINISTRATION}

U. S. Government Contract No. EY-76-C-04-0053 


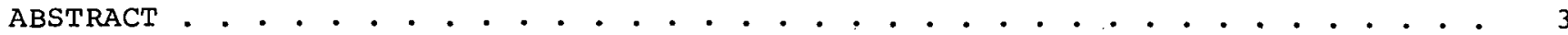

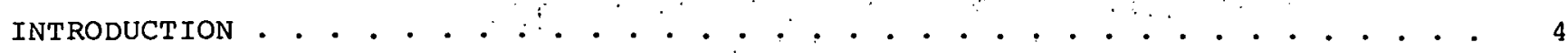

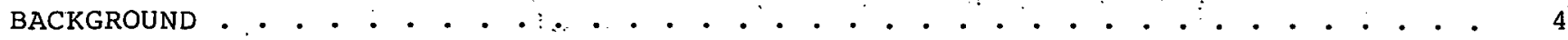

COMMERCIAL BONE CHAR . . . . . . . . . . . . . . . . . . . . . . . . . . . . . 6

REACTION OF PLUTONIUM WITH BONE CHAR AS A FUNCTION OF pH • • • • • • • • . . . . 7

General Experimental Procedure. . . . . . . . . . . . . . . . . . . . 7

Bone Char-Water System. • . . . . . . . . . . . . .... . . . . . . 7

Plutonium oxidation States. . . . . . . . . . . . . . . . . . . . . . . . 10

The Adsorption of Plutonium(IV) Polymer by Glass Vessels.. . . . . . . . . . 11

The Adsorption of Plutonium(IV) Polymer by Bone Char as a Function

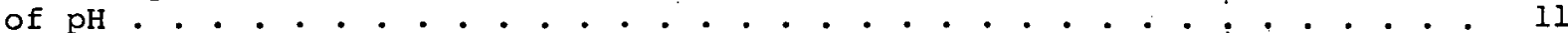

The Adsorption of Plutonium(IV) Polymer by Bone Char in the

Presence of Other Species . . . . . . . . . . . . . . . . . . . . . 16

The Adsorption of Hexavalent plutonium by Bone char as a Function of pH.

ADSORPTION ISOTHERMS OF BONE CHAR WITH URANIUM AND PLUTONIUM . • . . . . . . . . 24

The Nature of Adsorption Isotherms Representing the loading of Bone

Char with Uranium and Plutonium. . . . . . . . . . . . . . . . . . . . 24

Procedures Used in the Determination of Adsorption Isotherms . . . . . . . 25

Adsorption of Uranium by Bone Char. . . . . . . . . . . . . . . . . . . . 25

Adsorption of Plutonium by Bone Char. . . . . . . . . . . . . . . . . . . . 28

Summary of Isotherm Experiments . . . . . . . . . . . . . . . . . . . . . . 31

REFERENCES . . . . . . . . . . . . . . . . . . . . . . . . . . . . 33

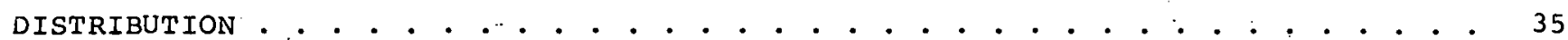




\begin{abstract}
A study of the reaction of plutonium with a commercial bone char indicates that this bone char has a high capacity for removing plutonium from aqueous wastes: The adsorption of plutonium by bone char is $\mathrm{pH}$ dependent, and for plutonium(IV) polymer appears to be maximized near pH 7.3 for plutonium concentrations typical of some waste streams. Adsorption is affected by dissolved salts, especially calcium and phosphate salts. Freundlich isotherms representing the adsorption of uranium and plutonium have been prepared. The low potential imposed upon aqueous solutions by commercial bone char is adequate for reduction of hexavalent. plutonium to a lower plutonium oxidation state.
\end{abstract}




\section{Introduction}

In 1973, a patent was granted to $\mathrm{H}$. W. Kirby for a procedure for decontaminating radioactive liquids by contacting the liquids with phosphate salts of various elements. 1 This idea, together with the observation that in the human body plutonium seems to accumulate in the bones, suggests that "bone char," a by-product of the processing of animal carcasses, might be a suitable material for removing plutonium from waste liquids. It was
Kirby who first suggested bone char as a material suitable for the decontamination of waste water, and it is the purpose of this report to describe experimental work designed to illuminate some properties of commercial bone char as a material for removing plutonium and uranium from waste water. Experimental work on the use of bone char for removing radioactive contamination from industrial waste water can be found in References 2 and 3 .

\section{Background}

One of the problems facing the nuclear industry is that of radioactive waste disposal. This problem includes the disposal of radioactive solid wastes as well as the removal of low levels of radioactivity from industrial wastewaters in an economical, rapid, and facile manner. A popular method of removing some radioactive elements from wastewaters is coprecipitation with iron hydroxide in the presence of a calcium salt. Unfortunately, this method may leave a small amount of radioactivity in the solution from which the iron and most of the radioelements are separated by the precipitation. For example, when solutions of plutonium and uranium are treated with ferric sulfate and then coprecipitated with the iron at $\mathrm{pH} 8.9$, a small amount of the plutonium and uranium will remain in the solution and escape through a filter bed of sand. In the cases of uranium and plutonium, this may be due to such factors as the solubility of the $\mathrm{MO}_{2}^{2+}$ hydroxides, the tendency of the $\mathrm{MO}_{2}^{2}+$ hydroxides to become colloidal, the existence of socalled "polymers" and colloidal particles of $M(I V)$, or even the existence of the elements in more soluble forms such as MOt. Whatever the nature or concentration of radioactive materials in waste waters, it would be desirable to have a means of reducing their concentrations before permitting the waste waters to be discharged to the environment.

Bone char, the commercial name given to one form of a calcium phosphate, occurs in the skeletons and teeth of vertebrates and occasionally in mineral deposits. Bone char, often prepared from the bones of cattle, has been used in the sugar industry as a decolorizing agent. The phosphate in bone char has the simple formula $\mathrm{Ca}_{5}\left(\mathrm{PO}_{4}\right)_{3}(\mathrm{OH})$. Another common name for the calcium phosphate in bone char is hydroxyapatite (HAP). Of course, when bone char is prepared from cattle bones, it may contain impurities introduced by the manufacturing process as well as the trace minerals which naturally occur in the bones of healthy animals. The hydroxy group in HAP may be replaced with fluoride ions to form fluoroapatite, such as occurs in the process of hardening teeth.

Ever since HAP was identified as the primary constituent of human teeth and young bones, it has been the subject of much study. There is a considerable literature on HAP, and it is common to find research on this material originating in dental or medical schools. The processes of caries formation and the embrittlement of bones with advanced age involve reactions of or transformations within HAP structures, and the phenomenon of tetany may involve the rate of dissolution of HAP.

Long ago, it was observed that the condition of tetany was related to the product of the concentrations of calcium and phosphorous in blood. As a result of this observation, the solubility of HAP was investigated, and over the years, many papers related to studies of the solubility of HAP have appeared. At first glance, it would appear that a subject so well researched would be relatively well understood. This is certainly not the case, however, as there is considerable disagreement over the mechanism of dissolution and the nature of the equilibrium of HAP on contact with water or water containing salts such as sodium chloride. What is agreed upon is that HAP slowly dissolves in aqueous, solutions to yield calcium and phosphorous concentrations which are often in the range $10^{-3}-10^{-5} \mathrm{M}$ near $\mathrm{pH} 7$. Beyond this, there 
is little agreement on anything. For convenience, opinions on the solubility of HAP may be broken into the following four categories:

A. The HAP-water system does not reach thermodynamic equilibrium in reasonable time periods (up to a few months): the amount of dissolved calcium and phosphorous depends upon the amount of solid HAP in contact with the solution and the solubility is "incongruent." This view is held by Levinskas and Neuman" who found that the concentration of calcium dissolved from HAP could be as high as $15 \times 10^{-4} M$ in suspensions containing $100 \mathrm{~g}$ of $\mathrm{H} \overline{\mathrm{AP}}$ per liter of solution near $\mathrm{pH} 6.5$. It was found that the concentration of dissolved calcium decreased as the mass of HAP in the solution decreased and also as the $\mathrm{pH}$ of the solution increased. They also found that sodium ions can apparently displace calcium ions from HAP, and that HAP acted as a buffer upon the solutions into which it was placed. That is, acidic and alkaline solutions suffered $\mathrm{pH}$ increases and decreases, respectively, when placed in contact with HAP for a period of a few days. The action of HAP is such that it adjusted extreme values of $\mathrm{pH}$ to values which were closer to the neutral point.

B. HAP reacts with water to form a surface layer of $\mathrm{Ca}_{2}\left(\mathrm{HPO}_{4}\right)(\mathrm{OH})_{2}$. This view is held by Rootare, Deitz, and Carpenter, ${ }^{5}$ who also observed that solution composition is not only dependent upon the amount of solid HAP in contact with the solution, but upon total ionic strength as well. According to them, HAP dissolves to form a surface complex, $\mathrm{Ca}_{2}\left(\mathrm{HPO}_{4}\right)(\mathrm{OH})_{2}$, as follows:

$\mathrm{Ca}_{5}\left(\mathrm{PO}_{4}\right)_{3}(\mathrm{OH})+3 \mathrm{HOH}$

$=2 \mathrm{Ca}_{2}\left(\mathrm{HPO}_{4}\right)(\mathrm{OH})_{2}+\mathrm{Ca}^{2+}+\mathrm{HPO}_{4}^{2-}$

followed by some dissolution of the surface complex

$\mathrm{Ca}_{2}\left(\mathrm{HPO}_{4}\right)(\mathrm{OH})_{2}$

$$
=2 \mathrm{Ca}^{2+}+\mathrm{HPO}_{4}^{2-}+2 \mathrm{OH}^{-}
$$

and the apparent solubility of HAP can be explained in terms of reaction (1). A defense of this hypothesis has been written by LaMer. ${ }^{6}$

C. The solubility of HAP is like that of any normal solid; previous anomalies are caused by impure samples and failure to include all pertinent corrections, such as ion palr formation.
Clark, long ago, reported that a reproducible solubility product characteristic of stoichiometric dissolution of HAP can be experimentally observed. ${ }^{7}$ Moreno, Gregory, and Brown are also exponents of this point of view, ${ }^{8}$ although they found that different samples of HAP gave different solubility products, a phenomenon perhaps attributable to differences in various preparations of HAP. That is, their "as prepared" HAP did not fit their dissolution model very well; however, that is a point worth remembering when dealing with "as prepared" commercial samples. Their case, unfortunately, is weakened for the uninformed reader by their obscure equations, for which only limited development and background are presented. Moreover, Moreno, et al, would have done well to try various solid/liquid ratios to test their ideas as other experimenters have done: Wier, Chien, and Black apparently concur that HAP has the solubility product characteristic of a solid which dissolves normally, 9 but their data indicated more than one possible solubility product for HAP which they explain by proposing that HAP may exist in somewhat different forms with each form having its own characteristic activity.

D. HAP dissolves by some means not included in the other categories. There is no shortage of theories to explain the curious solubility behavior of HAP. An interesting paper by Francis has summarized some of these hypotheses.10 Francis, moreover, presents some experimental work of his own, 10 which he interprets to mean that HAP is covered by a surface layer of hydrated calcium acid phosphate, $\mathrm{CaHPO}_{4} \cdot 2 \mathrm{H}_{2} \mathrm{O}$. Amin has confirmed the slurry density effect (ratio of solid to liquid) upon HAP solubility, reviewed previous work, and discovered a curious inhibition of HAP dissolution by phosphate ions. 11 $\mathrm{Zimmerman}$ has criticized the surface complex hypothesis, 12 and wier has critically reviewed much previous work on HAP. ${ }^{3}$ In addition, Wier ${ }^{13}$ has provided his own evidence of the importance of the solid/solution ratio upon the solubility of HAP. $Z$ immerman has reviewed a paper by Best and Hearon, who, according to Zimmerman, also maintain that HAP has no unique solubility product. 12 According to $\mathrm{zimmerman's} \mathrm{review,} \mathrm{Best}$ and Hearon ${ }^{14}$ believe the solubility of HAP depends upon the surface-tovolume ratio of solid HAP, on the 
stoichiometric proportions of calcium and phosphorous in the HAP, and the thickness of the "crystal surface" phase.12,14 Zimmerman also provides his own interpretation of the solubility of HAP based upon kinetic considerations. 12

From the abundant and contradictory data and from the interpretations and theories surrounding HAP, it can probably be concluded that the extent and mechanism of. dissolution of this material is an issue which is not yet settled. That is indeed unfortunate, for the study of this material in waste streams is rendered more difficult when the behavior of HAP in water is not clearly understood. Still other references to the solubility behavior of HAP can be found as literature citations in each of the studies specifically referenced above. Other studies of HAP include investigations of the solubility of this material when it occurs naturally as a rock. 15,16 The rate at which HAP dissolves has been studied, 17,18 as have various laboratory preparations of this material, 19,20 the alkaline earth phosphates have been generally reviewed, 21 and the heat of formation of HAP has been estimated. 22 It is curious that so common a substance as HAP could be the subject of so much study and yet remain a matter of so little understanding. Other studies of hydroxyapatite have considered ion exchange reactions with calcium, 23,24 phosphorous, 25 strontium, 26 and sodium. ${ }^{2}$ Additionally adsorption characteristics of bone char have also been examined. 28,29

\section{Commercial Bone Char}

The HAP (hydroxyapatite) used in the study of the removal of radionuclides from waste streams is a natural bone char obtained from the Kerr-McGee Corporation. Since it is a commercial product, it cannot be expected to match the theoretical analysis of HAP $(39.98 \mathrm{Ca}, 18.58 \mathrm{P})$. Table 1 gives the analysis of the bone char to be used in the present work.

It was not possible from the $x$-ray powder diffraction pattern to determine whether the calcium phosphate in the bone char was $\mathrm{Ca}_{5}\left(\mathrm{PO}_{4}\right)_{3} \mathrm{OH}$, (HAP) or $\mathrm{Ca}_{3}\left(\mathrm{PO}_{4}\right)_{2} \cdot \mathrm{nH}_{2} \mathrm{O}$ (file numbers $9-432$ and $18-303$, respectively). because the powder diffraction pattern of the bone char resembled. the powder patterns of both phosphates very closely. The bone char was crystalline, however, as it produced 26 sharp x-ray diffraction lines. The $\mathrm{Ca} / \mathrm{P}$. weight ratio in HAP is 2.156 and in the bone char it was 2.153; this rules out $\mathrm{Ca}_{3}\left(\mathrm{PO}_{4}\right)_{2} \cdot \mathrm{nH}_{2} \mathrm{O}$ as the principal constituent in the bone char and establishes that HAP was the major constituent.
Table 1

COMPOSITION AND PROPERTIES OF A COMMERCIAL BONE CHAR

\begin{tabular}{|c|c|}
\hline Element & 8 \\
\hline $\mathrm{Ca}$ & 33.8 \\
\hline $\mathbf{P}$ & 15.7 \\
\hline $\mathbf{H}$ & 0.4 \\
\hline$S$ & 0.03 \\
\hline $\mathrm{Na}$ & 2.4 \\
\hline $\mathbf{N}$ & 1.0 \\
\hline Carbonate & 5.0 \\
\hline C & 5.8 \\
\hline $\mathrm{Mg}$ & 0.5 \\
\hline $\mathbf{s i}$ & 0.3 \\
\hline Mn & 0.05 \\
\hline $\mathrm{Fe}$ & 0.1 \\
\hline
\end{tabular}

$\begin{array}{ll}\text { Internal Porosity, \& } & 50-55 \\ \text { External Void Fraction } & 18 \\ \text { Bulk Dry Density, lb/ft } & 40 \quad\left(0.641 \mathrm{~g} / \mathrm{cm}^{3}\right) \\ \text { Surface Area, } \mathrm{m}^{2} / \mathrm{g} & 100-115 \\ \text { Typical Uses } & \text { Decolorizing of } \\ & \text { crude sugar } \\ & \text { syrups removal } \\ & \text { of salts or } \\ & \text { "ash" from pro- } \\ & \text { cess streams }\end{array}$




\section{Reaction of Plutonium with Bone Char as a Function of $\mathrm{pH}$}

\section{GENERAL EXPERIMENTAL PROCEDURE}

Portions of commercial bone char were sieved and washed by passing water through standard sieves containing ground bone char. The powder thus sized to 75104 microns was dried overnight at $150^{\circ} \mathrm{C}$. One-gram portions of this material were transferred to $100-\mathrm{ml}$ volumetric flasks, a portion of buffer added to adjust the solution $\mathrm{pH}$, a sample of standard plutonium solution added, and the samples allowed to stand for one week with frequent daily shaking to hasten equilibrium. Such solutions were then allowed to stand for two days before sampling and counting. All counts were for 100-min intervals unless noted otherwise. The $\mathrm{pH}$ values of the equilibrated solutions were measured with a Leeds and Northrup $\mathrm{pH}$ meter with individual glass and calomel electrodes, or with a corning $\mathrm{pH}$ meter with a combination glass-reference electrode. Ethylenediamine and ammonia, as the chlorides or nitrates, were used as $\mathrm{pH}$ buffers except as noted otherwise. These buffers have the advantage that, during the course of an experiment, $\mathrm{pH}$ adjustment of the solutions did not result in a pronounced change in the ionic strength of the solutions :

$$
\mathrm{NH}_{4}^{+}+\mathrm{KOH}=\mathrm{NH}_{4} \mathrm{OH}+\mathrm{K}^{+}
$$

and the further advantage that ammonium and ethylenediammonium cations are not likely to undergo substitution reactions with the constituents of the bone char.

The disintegration rate of plutonium solutions exposed to bone char was obtained with a "Tri-Carb" scintillation counter manufactured by the Packard Instrument Company. "Instagel" scintillation and gelling agent was used to suspend the aqueous samples mixed with a portion of distilled water so that the aqueous phase had a volume of $10 \mathrm{ml}$, while the volume of the organic "Instagel" phase was $15 \mathrm{ml}$. Except as otherwise noted, all solutions were counted in tightly capped glass vials. The isotopic composition of the plutonium was about 808 plutonium-238 and 208 plutonium-239.

\section{THE BONE CHAR-WATER SYSTEM}

As bone char is a calcium phosphate with a finite solubility, the dissolution of this material results in a solution buffered by phosphate ions, as well as other ions, such as carbonate, which may dissolve from commercial bone char upon prolonged exposure to water. Since commercial bone char is prepared from animal bones, however, and retains some organic matter (as indicated by the analysis shown in Table 1), it is perhaps not surprising that bone char, in addition to acting as a pH buffering agent, also acts as a potential buffer, weakly imposing a low potential upon the solution in which it dissolves.

One of the important parameters determining the behavior of plutonium with bone char is the effect which the bone char exerts upon its environment. In the case of the reaction of plutonium with the commercial bone char studied here, the manner in which the bone char affects the trace of aqueous plutonium is of primary importance. Since alkaline solutions are of interest, several solutions with $\mathrm{pH}$ values from about 9 to 11 (with ammonia buffer) were prepared. Each 100-ml buffer also contained a $1-g$ sample of commercial bone char. After a five-day equilibrium period, during which the samples (in 100-ml volumetric flasks) were shaken repeatedly, the $\mathrm{pH}$ and electromotive force values of the solutions were measured. (EMF values were taken using a ferricyanide/ferrocyanide buffer assigned a potential value of $+0.41 \mathrm{~V}$.)

The above experiments were repeated several times, using other buffering systems. Figure 1 shows the results with an ammonia/ ammonium nitrate buffer, Figures 2 and 3 with an ammonia/ammonium chloride buffer, and Figures 4 and 5 with a potassium carbonate/bicarbonate buffer. In each diagram, the points drawn as circles (lower line) represent the potential $\mathrm{pH}$ values of solutions as measured about two minutes after uncapping the samples. Points marked with 's (upper line) were taken after about three minutes of stirring while exposed to atmospheric oxygen (that is, about five minutes after uncapping the sample). In these experiments, it is the potential, not the $\mathrm{pH}$, which changes upon exposure to the atmosphere. In all of the diagrams, lines with a given slope of -0.059 are passed through the points. A line with slope +0.059 is the theoretical Nernstian value at $\left(25^{\circ} \mathrm{C}\right)$ for a reversible reaction involving a proton/ electron ratio of unity. Other possible, likely values of the absolute value of the slope are the factor \pm 0.059 times some simple number or fraction such as $1 / 3,1 / 2,4 / 3,2$. Since bone char is known to contain organic matter from animal bones, there is no way of predicting the value of the slope. The points seem to follow the slope -0.059 quite well, however, suggesting that the 


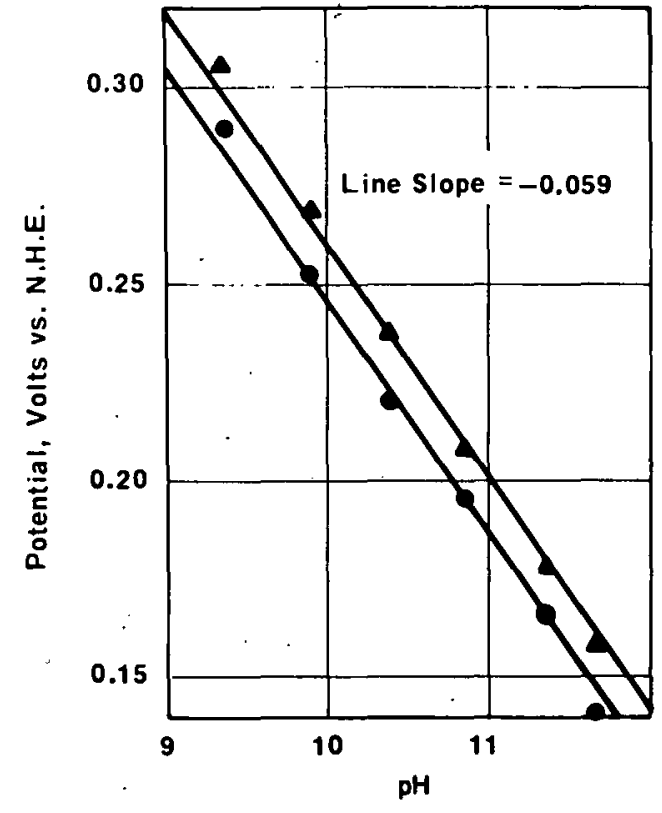

FIGURE 1 - The bone char-water system in an $\mathrm{NH}_{3}-\mathrm{NH}_{4} \mathrm{NO}_{3}$ buffer.

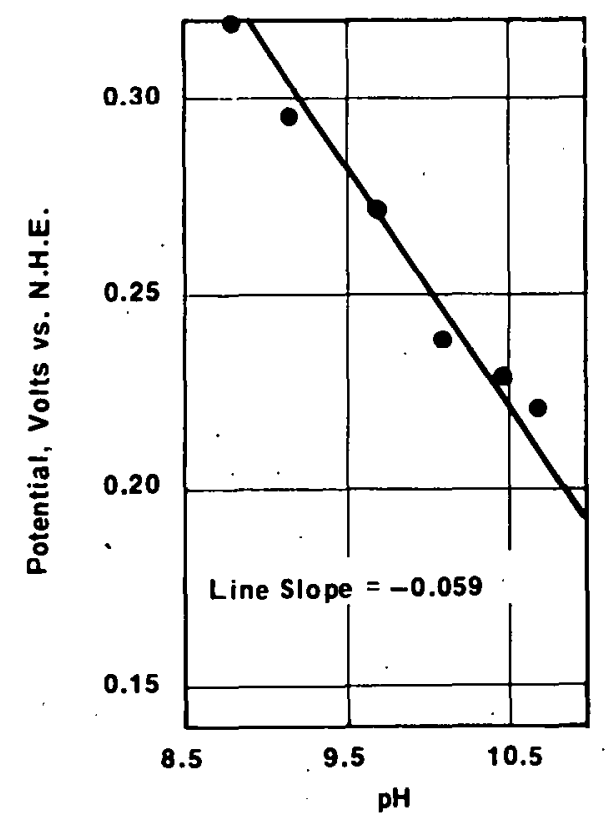

FIGURE 3 - The bone char-water system in a small amount of $\mathrm{NH}_{3}-\mathrm{NH}_{4} \mathrm{Cl}$ buffer.

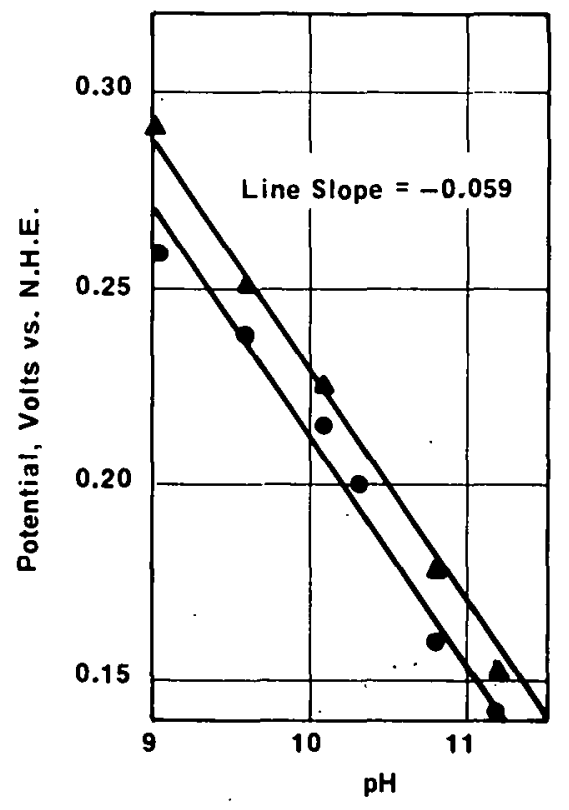

FIGURE 2 - The bone char-water system. in a moderate amount of $\mathrm{NH}_{3}-\mathrm{NH}_{4} \mathrm{Cl}$. buffer.

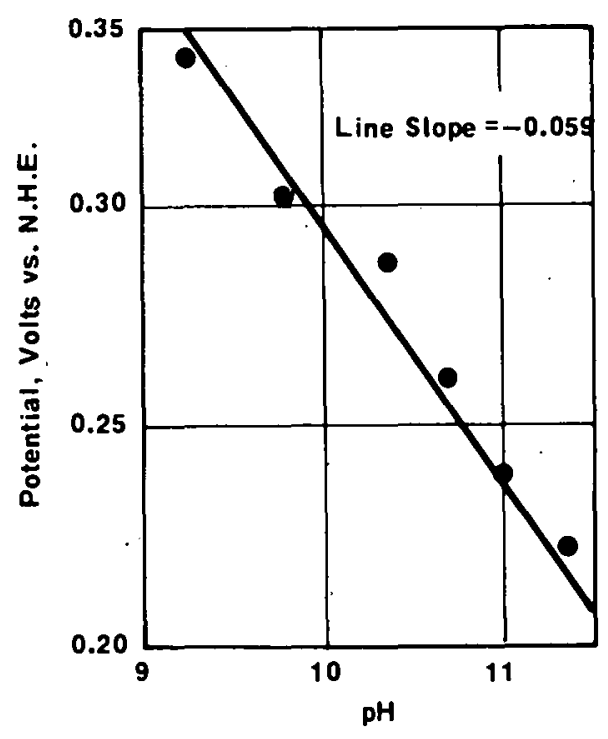

FIGURE 4 - The bone char-water system in a $\mathrm{K}_{2} \mathrm{CO}_{3}$ buffer 


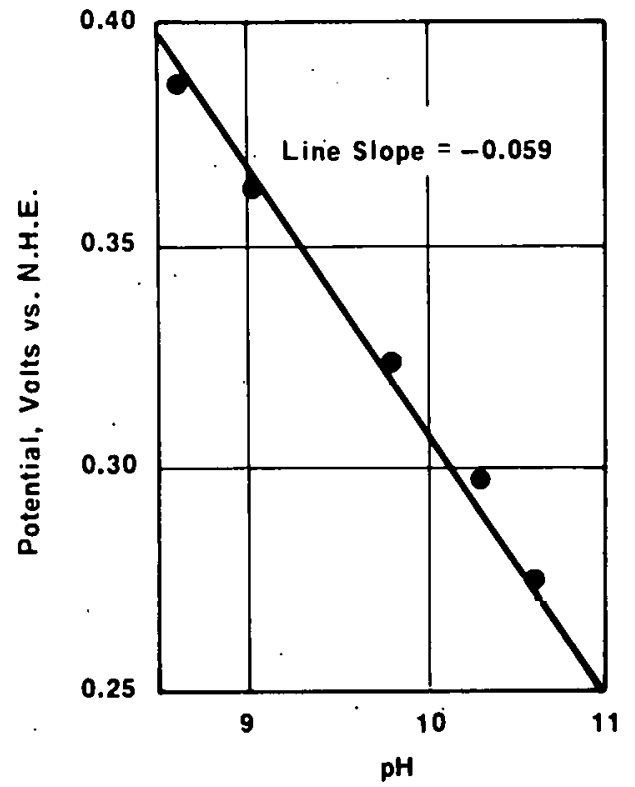

FIGURE 5 - The bone char-water system in a $\mathrm{KHCO}_{3}$ buffer.

potential controlling reaction is generally of the form

$$
\mathrm{Ox}+\mathrm{ne}=\operatorname{Red}-\mathrm{nH}^{+},
$$

where "Ox" and "Red" represent the oxidized and reduced forms of the potential controlling reaction, and "e" represents an electron.

The plots in Figures 1-5 suggest certain properties of the bone char/water system. Among these are:

(a) Bone char imposes a low potential upon aqueous systems. At $\mathrm{pH} 10$ this potential for fresh solutions is about $+0.25 \mathrm{~V}$, a value characteristic of some organic systems.

(b) The behavior of the potential-controlling reaction appears to be poorly reversible and appears to follow the form suggested by Equation (4).

(c) The fact that the potential drifts slowly upward upon exposure to atmospheric oxygen implies that the system is oxidized by air, and that the poising capacity of the bone char-water system is very low.
In order to check that the potential-pH behavior of the bone char samples described above were not a peculiarity of one particular bone char specimen, new samples of bone char were prepared, sized to 74-105 microns with standard sieves, and washed several times with water to. remove fines. To ascertain whether the new samples of bone char had properties which approximated :the previous samples, the potential$\mathrm{pH}$ behavior of the new samples was examined. Figure 6 shows this potential-pH behavior in a carbonate buffer, whereas Figure 7 shows this behavior in a phosphate buffer.

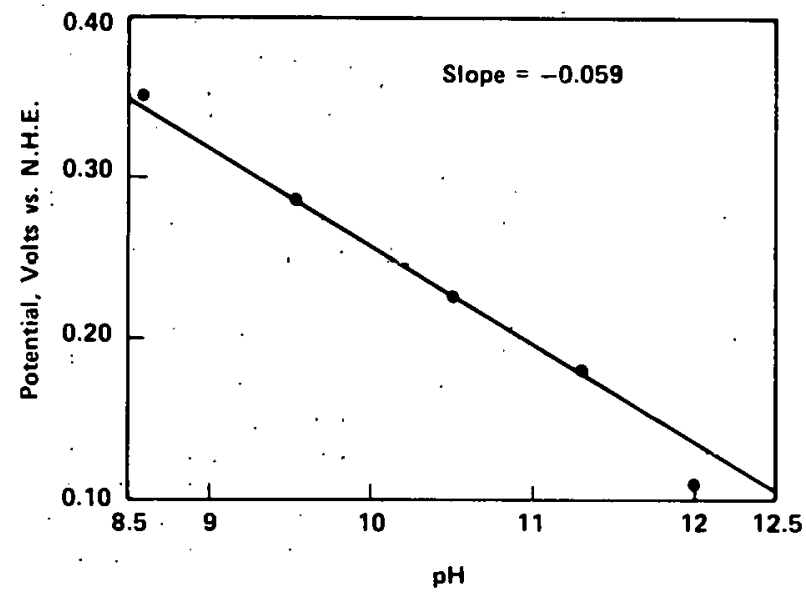

FIGURE 6 - Potential-pH behavior of bone char containing trace plutonium and carbonate buffer.

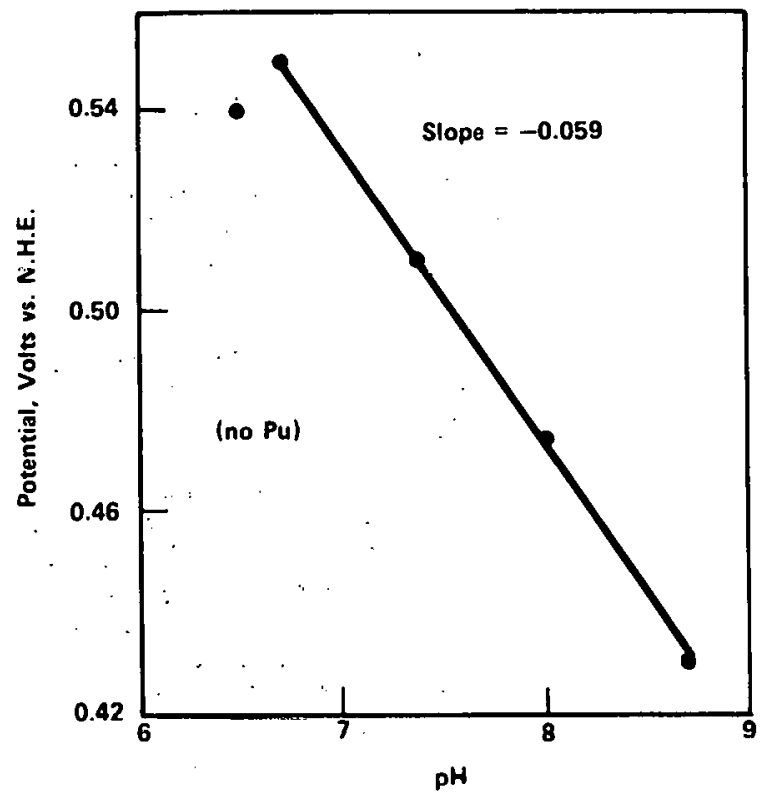

FIGURE 7. - Potential-pH behavior of bone char (phosphate buffer). 
The potential increased with decreasing pH in the expected manner, which indicated that this potential-pH behavior seems to be intrinsic to the bone char system and does not seem to be affected by screening and washing the bone char, but whether this potential-pH behavior is the same for bone char obtained from other commercial sources is not known. The new samples indicated the same low poising capacity as previous samples, that is, all of the potentials drift upwards upon exposure to air, so that the observed potential values depend upon the time of potential measurement. As indicated by Figures 6 and 7, however, if the procedure for taking potential measurements is standardized, linear plots can be obtained. Because of the potential instability and apparent dependence upon exposure to atmospheric oxygen, it seems likely that the potential may be of limited usefulness for quantitative description of the bone char-water-plutonium system, although it may be useful for purposes such as qualitative explanations and for suggesting new approaches to the problem of the equilibration of plutonium species with commercial bone char. For this reason, little use was made of potential measurements upon systems of bone char and water containing plutonium.

\section{PLUTONIUM OXIDATION STATES}

Plutonium can probably occur in waste water in any or all of four oxidation states. The likelihood of occurrence of any particular oxidation state in an aqueous solution depends upon several factors: the solution $\mathrm{pH}$, the solution oxidation-reduction potential, and the presence of complexing agents in the solution. It seems that mathematical methods for the comprehensive solution of the problem of equilibrium plutonium valence state distributions have been suggested only recently. These new approaches indicate that in neutral or alkaline solutions, such as are likely to occur with present methods of waste treatment (coprecipitation with ferric hydroxide at a high $\mathrm{pH}$ ), the two oxidation states of plutonium which are most likely to occur are tetravalent or hexavalent. Polymeric plutonium(IV) is the form of tetravalent plutonium which is conventionally considered the most likely form of tetravalent plutonium in neutral or alkaline waste water, and it is this form of plutonium which has been studied most extensively.

Initial experiments consisted of preparing plutonium(IV) polymer by treating a plutonium solution of unknown valence distribution as follows:
About 50-100 $\mathrm{mg}$ of sodium nitrite were added to about $5 \mathrm{ml}$ of plutonium-238 stock solution (oxidation state unknown) in $6 \mathrm{M}$ nitric acid. This solution was then diluted with 20-25 ml of concentrated (16M) nitric acid. The solution that resulted was then stirred and heated on a hot plate until evaporation had reduced the volume of the solution to about $2 \mathrm{ml}$. This solution was then cooled and treated with the various test procedures shown in Table 2. Table 2 describes various test procedures for preparing tetravalent plutonium polymer, but it is important to observe that the results quoted in the table are not reproducible. However, since boiling the plutonium solution at $\mathrm{pH} 12.5$ seemed to give the greatest radioactivity decrease upon centrifugation in these preliminary studies, it was decided to use this technique to examine plutonium solutions in the presence of bone char, assuming that the technique did yield solutions of plutonium(IV) polymer.

Plutonium solutions prepared by boiling in potassium hydroxide were used to try to ascertain the optimum $\mathrm{pH}$ range for removing plutonium from waste water with bone char in early experiments. Later experiments indicated that plutonium polymer prepared as described above, and plutonium known to be polymeric, were very similar in so far as their behavior with bone char was concerned. However, where plutonium polymer prepared as described above was used in bone char experiments, it appears in quotation marks. This distinguishes it from plutonium known to be polymeric, the preparation of which is now described.

About $5 \mathrm{~g}$ of plutonium(IV) nitrate in nitric acid (isotopic composition of the plutonium was about 808 plutonium-238 and 208 plutonium-239) was precipitated by the addition of ammonium hydroxide. The hydroxide was washed with water, and peptized in dilute nitric acid. Examination of the visible spectrum of this material indicated that the green solution contained plutonium(IV) polymer. No other oxidation states of plutonium could be detected in the spectrum. A diluted portion of this material was used in the study of plutonium(IV) polymer with bone char.

Solutions of hexavalent plutonium were prepared by treating unpolymerized tetravalent plutonium in nitric acid with divalent silver oxide. The brown solution so obtained was allowed to stand until the brown color disappeared, and the visible spectrum of a sample of the solution was examined to ascertain that the plutonium had been oxidized to the 
Table 2

TEST PROCEDURES FOR PREPARING PLUTONIUM(IV) POLYMER

Procedure Discription

Pour plutonium solution into $\mathrm{NH}_{3}$ buffer at $\mathrm{pH}$ maintained near 10

Pour plutonium solution into hot $\mathrm{NH}_{3}$ buffer at $\mathrm{pH}$ maintained near 10

Pour plutonium solution into boiling water and boil for $5 \mathrm{~min}$

Pour plutonium solution into a hot solution of $20 \mathrm{ml}$ of concentrated $\mathrm{NH}_{3}+80$ ml water, and then boil for one min.

Pour plutonium solution into $\mathrm{KOH}$ solution such that final $\mathrm{pH}$ is 12.5

Pour plutonium solution into $100 \mathrm{ml}$ of boiling water containing $\mathrm{KOH}$ such that final $\mathrm{pH}$ is 12.5

\section{*Alpha disintegrations}

hexavalent state. A portion of this solution was diluted with water for use in the study of hexavalent plutonium with bone char.

\section{THE ADSORPTION OF PLUTONIUM(IV) POLYMER} BY GLASS VESSELS

In order to differentiate between that plutonium which had been adsorbed by the walls of the glass vessels and that plutonium which.had been adsorbed by the bone char within the glass vessels, several experiments were undertaken to examine the extent of plutonium polymer adsorption by $100 \mathrm{ml}$ glass volumetric flasks. These experiments cursisted of preparing plutonium(IV) "polymer" solutions as described above, and allowing samples of such a preparation (buffered at the desired $\mathrm{pH}$ ) to remain in the flasks for several days. The contents of the flasks were periodically shaken and sampled. The adsorption of plutonium(IV) "polymer," as determined by such experiments, appeared to be primarily a high$\mathrm{pH}$ phenomenon, and, for solutions which remained in glass flaskg for only about. 7 days, adsorption by glass was not appreciable for solutions with $\mathrm{pH}$ values below about 10. Figure 8 graphically shows the approximate rate of adsorption of plutonium(IV) "polymer" by glass volumetric flasks as a function of time at
Percent Solution Radioactivity*

Decrease by Centrifugation at $10,000 \mathrm{rpm}$ for $10 \mathrm{~min}$

$$
\sim 2
$$

several selected $\mathrm{pH}$ values. Figure 9 shows that same data plotted in such a way as to illustrate that even at $\mathrm{pH} 10$ the alpha count rate for solutions stored as long as 20 days had not been substantially reduced by adsorption of the "polymeric" plutonium on the walls of the glass vessels.

THE ADSORPTION OF PLUTONIUM(IV) POLYMER BY BONE CHAR AS A FUNCTION. OF $\mathrm{pH}$

The accurate determination of very low concentrations of radioactive isotopes is a problem on which progress is still being made. Part of this problem is that raninactive decay is a random event, so that exactly the same number of disintegrations of a radioisotope rarely occur in two time periods of the same length. For a low count rate, such as, for example, 16 disintegrations per unit of time, one standard deviation may be taken as about 4 dis/time unit. An interval of two standard deviations, or the interval in which about 958 of a series of individual determinations may be expected to lie, may thus be expected to be only within about: +508 of the actual count. Greater accuracy may be obtained by accumulating a greater number of counts, at the expense of prolonged counting times. When, to this statistical limitation, are added such factors as sampling inaccuracies, 


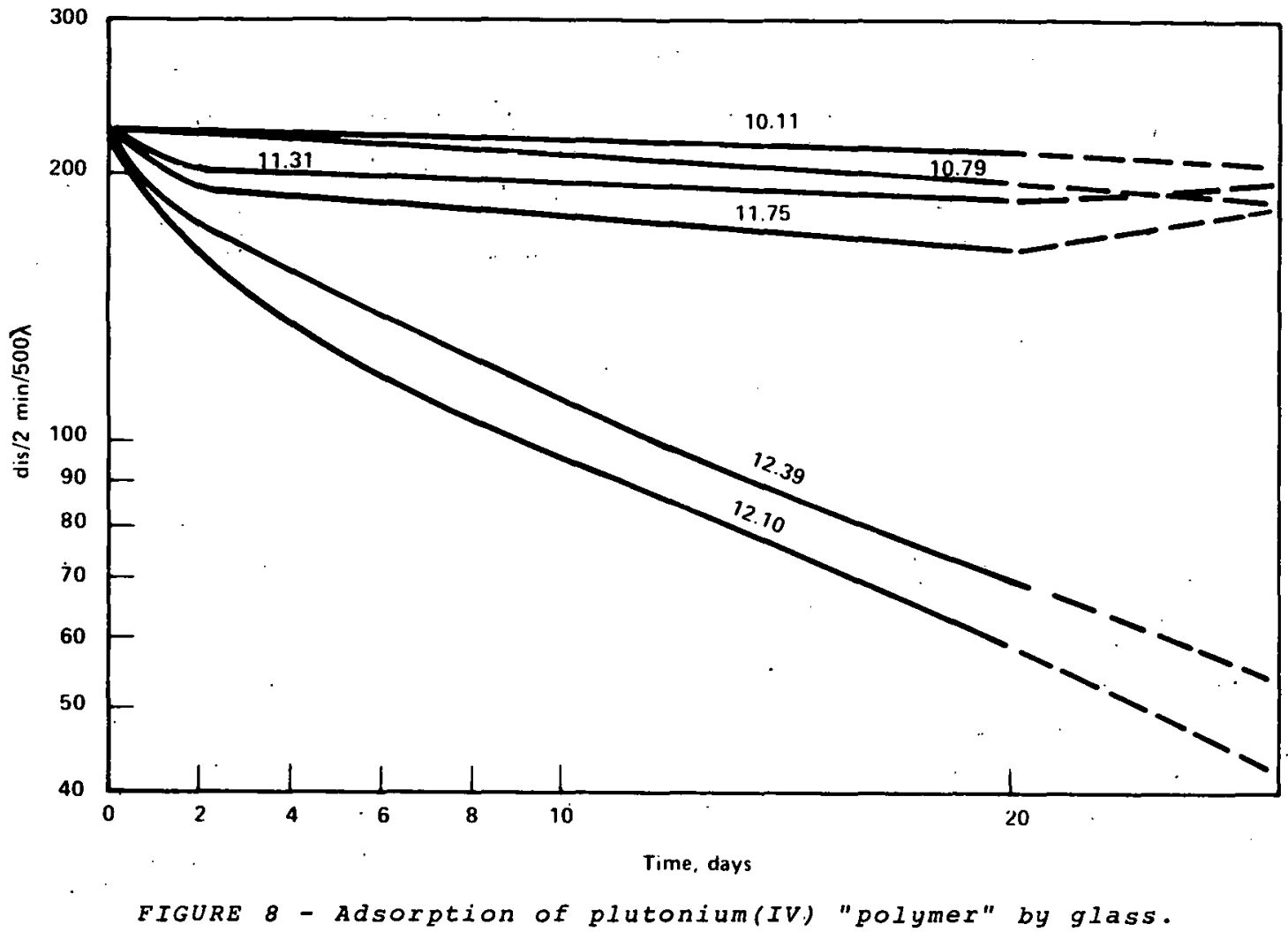

instrument imperfections, and the possibility of accidental contamination of samples, it is not surprising that some scatter in the count rates of solutions of low concentrations of radioisotopes is often observed. Bone char is such an effective agent for removing polymeric plutonium from aqueous solutions that plutonium solutions treated with this material retain only a trace of the original plutonium, and hence nave very low rates of alpha disintegrations... The count rate of such solutions has shown a degree of scatter or "irreproducibility" which at first seems disappointing, but the results of study of such solutions have not in general been so ambiguous as to preclude interpretation.

Irreproducibility of data accumulated in the study of the behavior of radiocolloids has been acknowledged for a long time. There is no simple, readily apparent reason why such data should always be characterized by scatter and be poorly reproducible, but irreproducibility seems, to be at least as common.in the study of radiocolloids as in other branches of chemistry and perhaps more so. Many workers in the field of radiochemistry have commented upon and attempted to explain the irreproducibility of data sometimes obtained from radiocolloids and sorption systems. There does not seem to

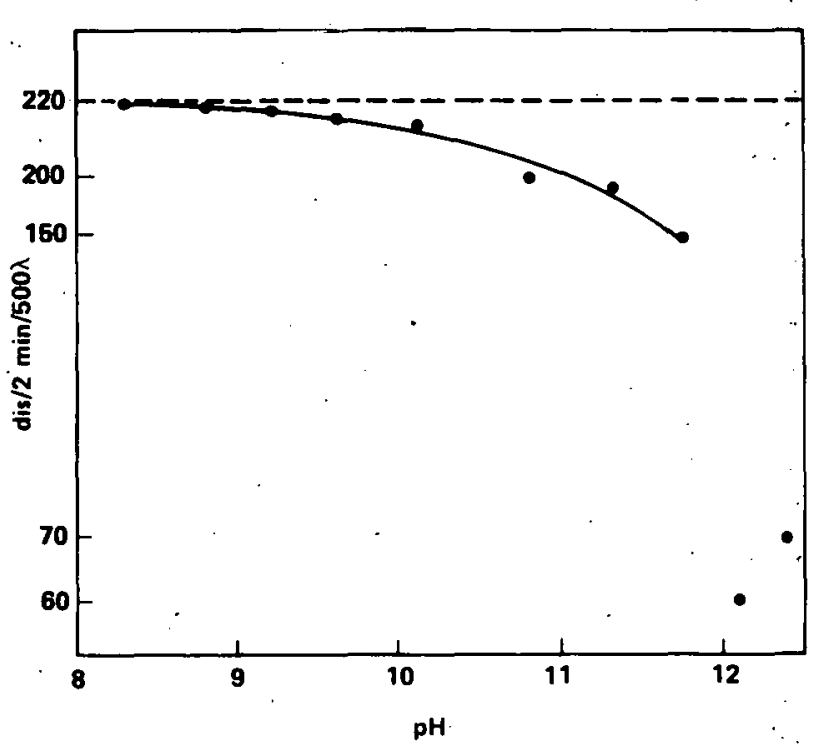

FIGURE.9 - Adsorption of plutonium(IV): "polymer" by glass count vs pH after 20 days equilibration (initial solution count given by dashed line). 
be general agreement on what causes irreproducibility of the behavior of radiocolloids, or how to avoid this circumstance. In many laboratory situations, the concentrations of the radiocolloids are often less than the concentrations of impurities in even the highest grade reagent chemicals, and it has been speculated that the behavior of radiocolloids can be attributed to radioelement adsorption upon the impurities present in even the best grades of commercial chemicals, or upon the surfaces of dust particles and the walls of vessels. Egorov has sumnarized this state of affairs in his statement that: "As a rule, the behavior of radiocolloids on sorption systems is anomalous." 30 In regard to radiocolloid systems and the anomalies often associated with them, Egorov states that: "this problem has in fact no solution." 30 Other workers have also remarked upon the difficulties that seem to be inherent in the study of systems of radiocolloids. Among these commenting workers may be found Mellish, Payne and Worrall, Andelman and Rozzel1, 32 and, in particular, Kepak, ${ }^{3}$ who has expressed the idea that radiocolloid systems may be examples of systems that are not in thermodynamic equilibrium.

In an attempt to reduce the scatter in the observed counting rate of samples of experimental solutions, samples were first centrifuged at $10,000 \mathrm{rpm}$ for about 10 min. This proved to be a time-consuming and tedious practice, a practice which led to occasional rupture of centrifuge tubes, and this attended by all the hazards of spilled radioactive liquids as well as loss of sample. While centrifugation had the effect of reducing the absolute count rate of the experimental solutions, it did not appreciably decrease the scatter which seemed to be intrinsic to the disintegration rate of the solutions. For this reason, the practice of centrifuying test sululions was abandoned. Solutions to be counted for residual radioactivity were allowed to stand undisturbed for two days prior to withdrawal of a small aliquot from the neck of the volumetric flask with a pipette.

A typical experiment illustrating the ability of bone char to adsorb plutonium(IV) polymer at various $\mathrm{pH}$ values is shown in Figure 10, which plots plutonium-238 counts per minute per $500 \lambda$ of $100 \mathrm{ml}$ solutions each containing $1 \mathrm{~g}$ of bone char. The various $\mathrm{pH}$ values were

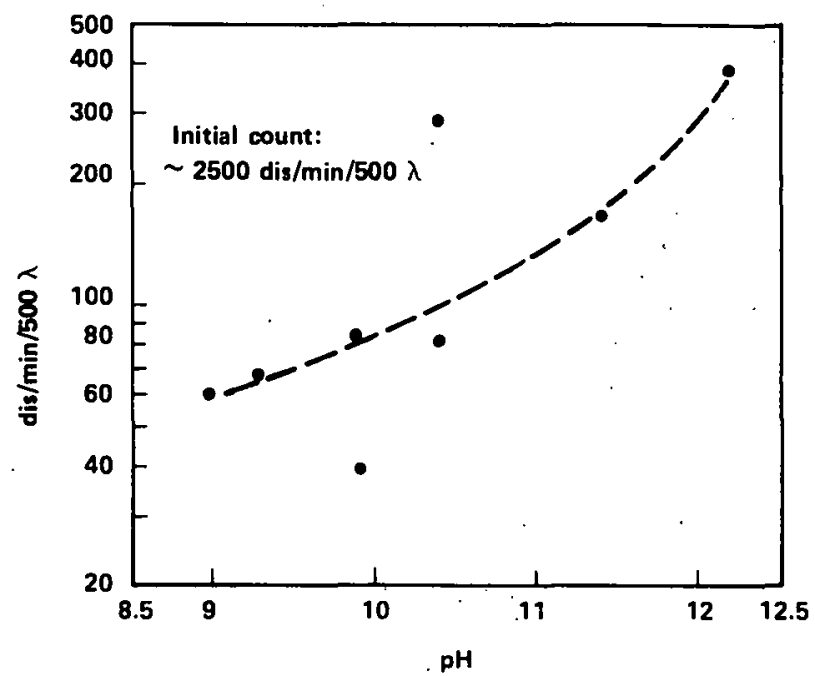

FIGURE 10 - Apparent bone char plutonium(IV) "polymer" equilibrium in ammonia buffer (all samples centrifuged).

obtained with ammonia buffer. Although the data are scattered, the fact that the activity in equilibrium with the bone char decreases with decreasing $\mathrm{pH}$ is evident. Prior to counting, each sample plotted in Figure 10 was centrifuged at $10,000 \mathrm{rpm}$ for $10 \mathrm{~min}$. Figure 11 shows the results

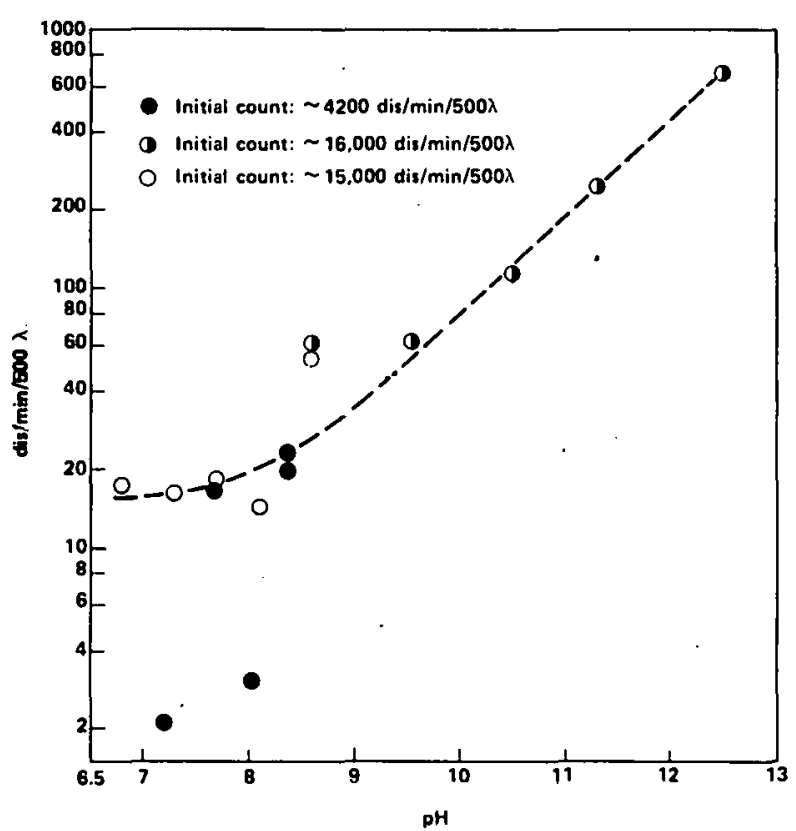

FIGURE 11 - Apparent bone char plutonium(IV) "polymer" equilibrium in carbonate buffer (all samples centrifuged). 
of a similar study in carbonate buffer. Figures 12 and 13 show other studies of the bone char-water-plutonium system in a ammonia buffer, but samples were not centrifuged prior to counting. Since there was no centrifugation step to remove large polymer particles, the absolute radioactivity level is increased; but the data again indicate that bone char as an absorbant for plutonium is more effective close to the neutral point than at high $\mathrm{pH}$ values.. Part of the scatter in the data points in Fig-. ures $10,11,12$, and 13 results from plotting together data obtained from different polymer preparations. As has been previously discussed in works on the chemistry. of plutonium, different preparations may lead to different degrees of polymerization; and this is probably as true of preparations that differ only in detail as. it is of preparations that differ in other than detail.

In order to examine the behavior of plutonium(IV) "polymer" (prepared by boiling in $\mathrm{KOH}$ as described above) in the presence of bone char near the neutral. point, two plutonium solutions were prepared for equilibrium in $100 \mathrm{ml}$ flasks with $1 \mathrm{~g}$ of bone char. Ethylenediamine was used as the buffer. Plutonium solu-

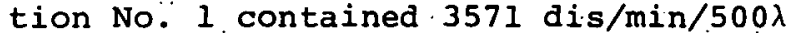

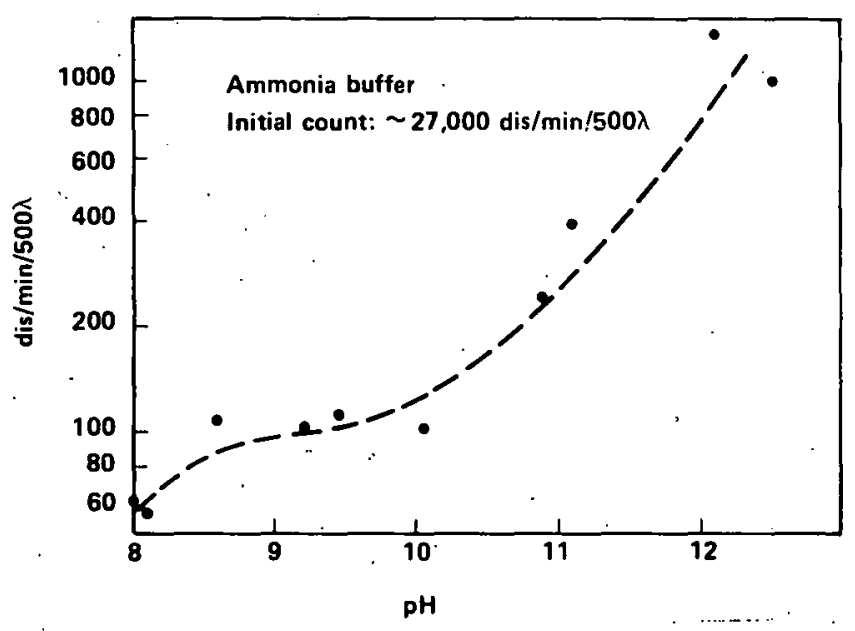

FIGURE 13 - Apparent adsorption of plutonium(IV) "polymer" by bone char as a function of $p H$ (samples not centrifuged) (dashed 1 ine represents one interpretation of data).

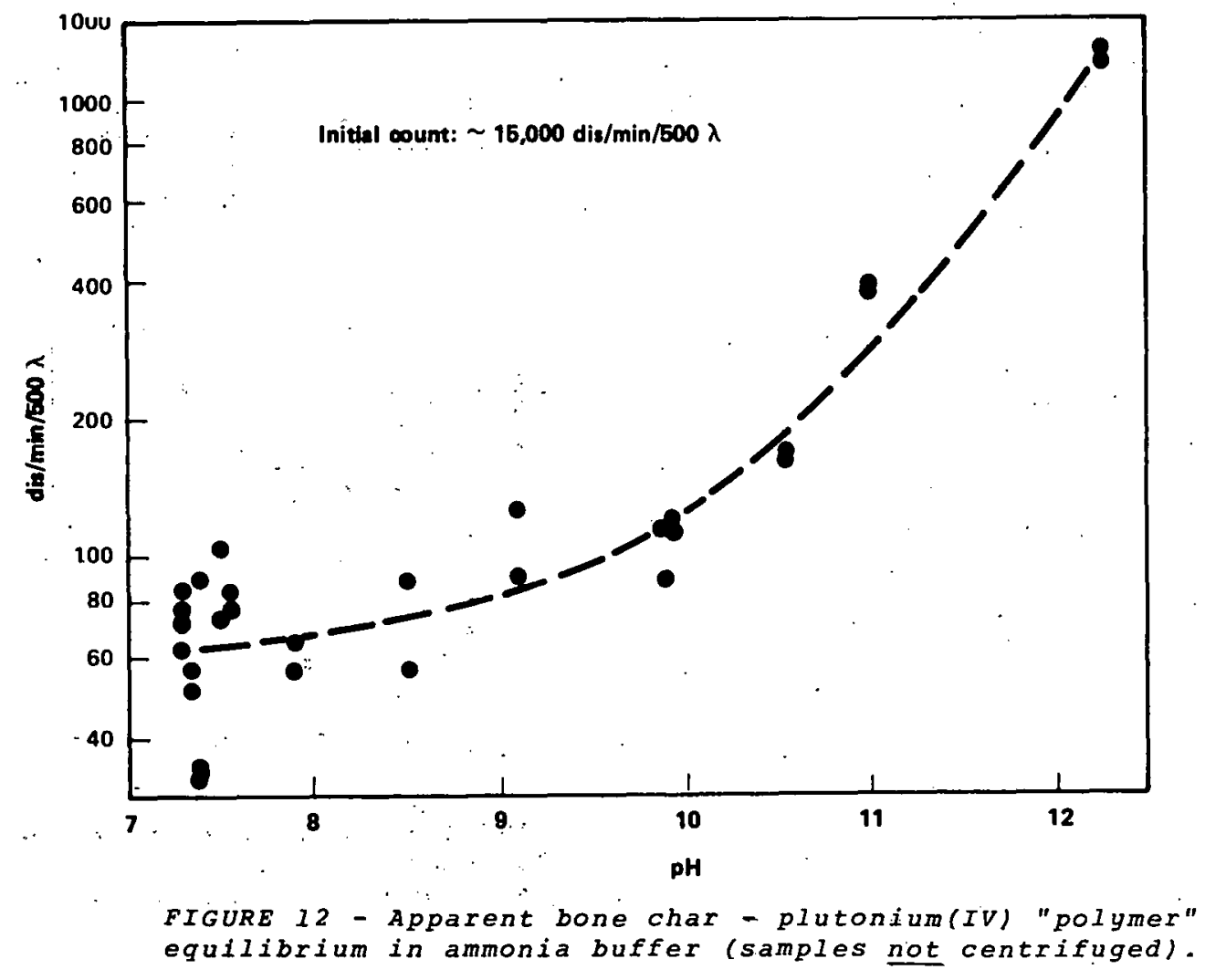


before reaction with bone char; and plutonium solution No: 2 contained 10,162 dis/min $/ 500 \lambda$ before reaction with bone char. The results of equilibrating these plutonium solutions with bone char are shown in Figure 14. As can be seen, considerable scatter is inherent in the data. However, the more dilute plutonium solution gave, on the average, a lower equilibrium count (about $15 \mathrm{dis} / \mathrm{min} / \mathrm{ml}$ ); and the plutonium solution with the higher initial count gave, on the average, a higher equilibrium count with bone char (about $23 \mathrm{dis} / \mathrm{min} / \mathrm{ml}$ ). It is difficult to obtain data at $\mathrm{pH}$ values much below $\mathrm{pH} 7$ because of the tendency of the bone char to dissolve and provide its own phosphate buffer. This self-buffering capacity of bone char tries to adjust. the $\mathrm{pH}$ to about 8 .

During the course of this study, it was observed that the apparent count rate of radioactive samples (stored in polyethylene vials containing the scintillating material and gelling agent) may gradually increase their count rate. This effect first became apparent with samples stored for more than $12 \mathrm{hr}$. However, this effect did not seem to occur in all samples or to occur uniformly in those samples in which the phenomenon was observed. It has been suggested that this phenomenon may be caused by the slow loss of toluene, a component of the scintillating fluid, through the walls of the polyethylene vilals when these vials are stored for long periods at room temperature. A study of this effect was not undertaken since it can apparently be avoided by using glass vials instead of polyethylene vials: In the few cases where the effect was observed, the count rate seemed to increase by about 10-208 in a 24-hr period. This effect may also be from temperature variations in the room, as the variations may encompass a span of $30^{\circ} \mathrm{F}$. Data in Figure 14 were obtained by counting all samplco in glass vials.

Further experimentation on the adsorption of tetravalent plutonium polymer by bone char confirmed that the adsorption process is pH dependent and that the adsorption is maximized near $\mathrm{pH}$ 7. A typical adsorption study for the plutonium(IV) polymer (prepared from plutonium(IV) hydroxide as described on page 10i) is shown in Figure 15, which plots residual solution artivity in a 100-ml flask

(that contains $1 \mathrm{~g}$ bone char) buffered with ethylenediamine hydrochloride and ammontum chloride. As can be seen from Figure 15, the point of maximum polymer adsorption is near pH 7; and adsorption decreases as pH increases or decreases from 7. The plot shows typical data

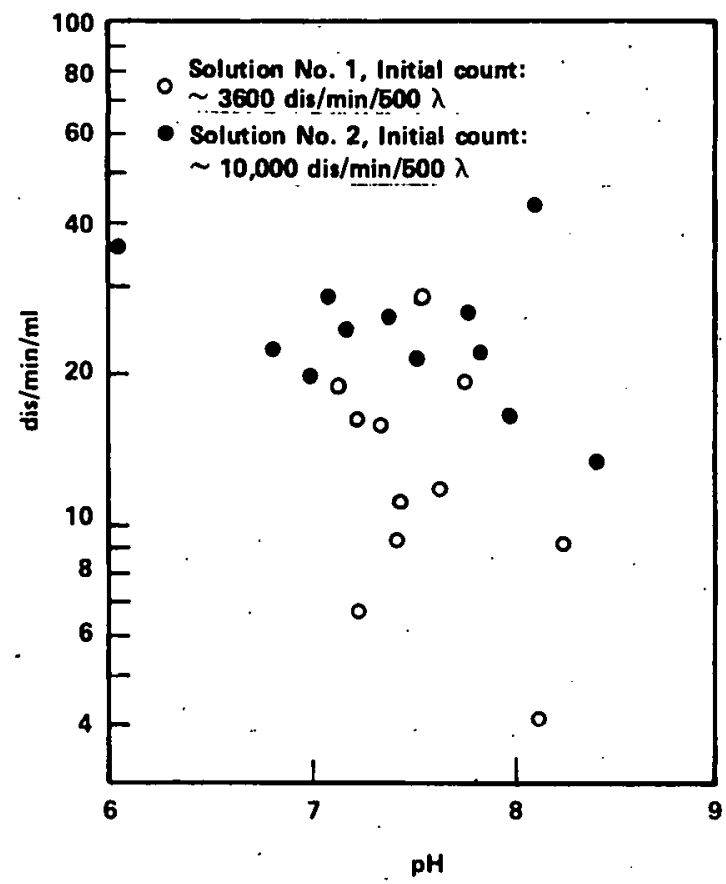

FIGURE 14 - Apparent equilibrium of plutonium(IV) "polymer" and bone char near the neutral point. (Open circles represent solution No. 1, closed circles represent solution No. 2. Ethylenediamine buffer, samples not contrifugod.)

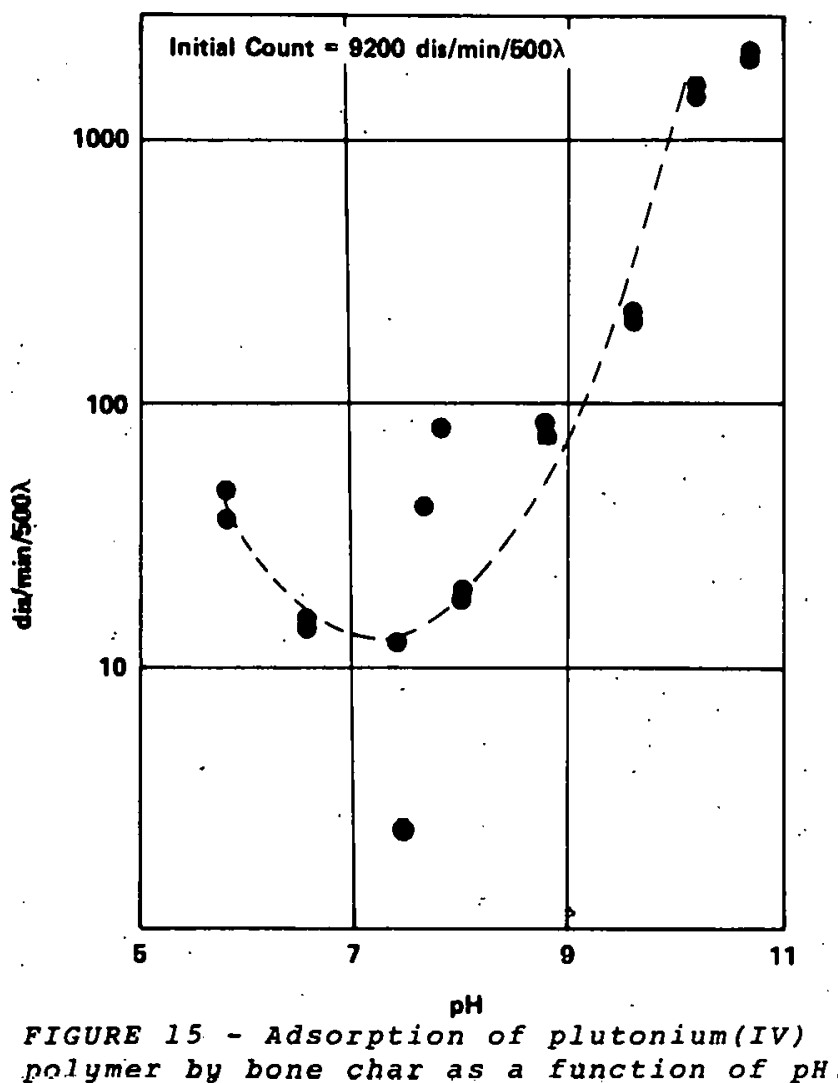


points with typical scatter in the count rate of solutions of very low levels of radioactivity, a phenomenon which has frequently been observed with plutonium and other radiotracers. Figure 16 shows the results of a similar experiment with a higher initial concentration of plutonium. The shape of the curve is similar to the curve in Figure 15, although the minimum corresponds to a higher final concentration of the plutonium. Careful examination of Figures 10-16 suggests that the $\mathrm{pH}$ of maximum adsorption of plutonium(IV) polymer by the commercial bone char is $\mathrm{pH} 7.3$.

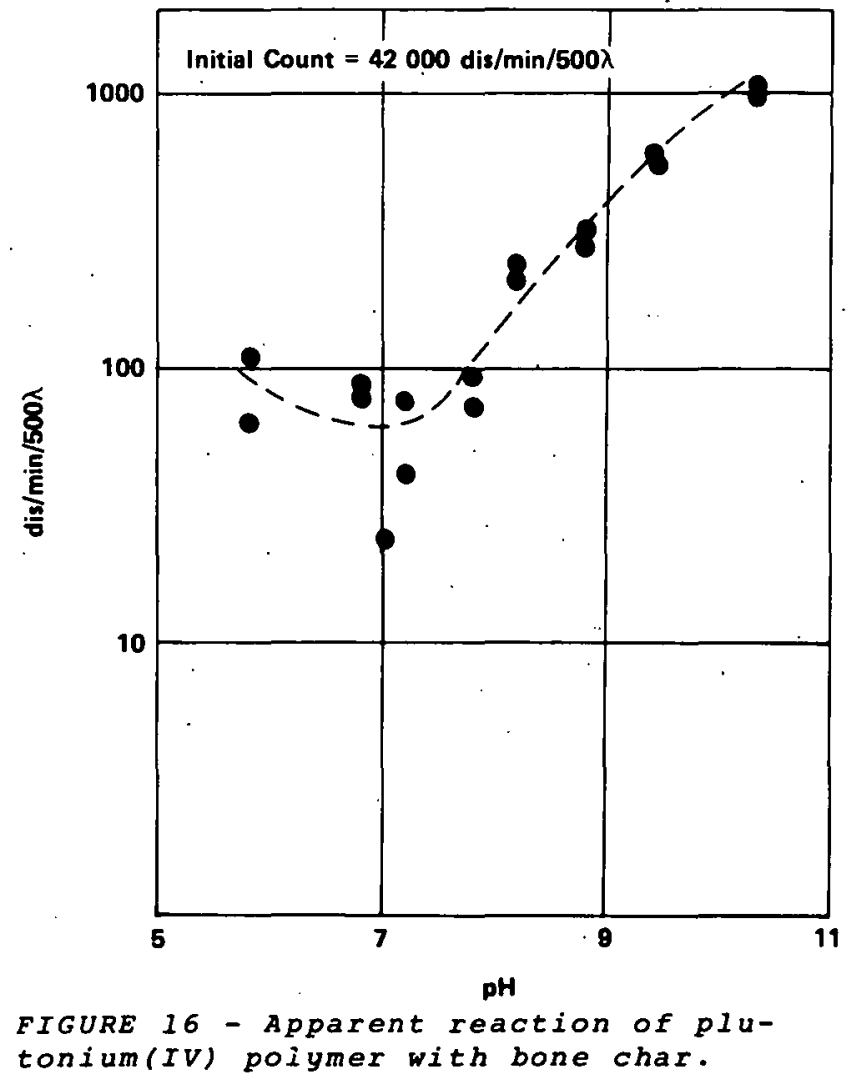

THE ADSORPTION OF PLUTONIUM(IV) POLYMER BY BONE CHAR IN THE PRESENCE OF OTHER SPECIES

Radioactive waste water, whatever its source, generally contains dissolved materials other than the radioactive pollutants. Even if not contaminated with nonradioactive solutes when the waste water is generated, nonradioactive solutes such as calcium salts are likely to be introduced by radioactive waste treatment facilities. Among the likely solutes which may be introduced into radioactive waste water are alkali halides such as sodium and potassium chloride. Figure 17 shows the adsorption of plutonium(IV) polymer by bone char in otherwise unbuffered water in the presence of various concentrations of potassium chloride. (The only pH buffering agents present in this system are species introduced by the dissolution of some of the bone char.) As can be seen from Figure 17, the adsorption of polymeric plutonium(IV) by the bone char is dependent on the presence of a salt such as potassium chloride. Bone char appears to show a slight minimum in its ability to adsorb plutonium(IV) polymer (i.e., a slight maximum in the residual solution count) at a potassium chloride concentration which is less than $0.1 M$, while polymer adsorption appears to slowly increase with increasing salt concentration for salt concentrations in excess of the salt concentration at the point of minimum adsorption. Figure 18 shows the adsorption of polymeric plutonium(IV) in the presence of various concentrations of sodium chloride. Again, the bone char-water system was devoid of buffering agents except those which derive from commercial bone char by the dissolution of this material. Figure 18 also shows a slight minimum in the ability of bone char to adsorb polymeric plutonium(IV). from sodium chloride solutions. At salt concentrations higher than the concentration at the point of minimum adsorption, the ability of the bone char to adsorb the polymer seems to increase and approach a limiting value. It may be concluded from Figures 17 and 18 that the adsorption of plutonium(IV) polymeric by commercial bone char is affected by the presence of salts which are often considered inert or nonreactive. In both experiments, the $\mathrm{pH}$ of the solutions was very close to $\mathrm{pH}$ 7.9 throughout the ranges of alkali halide concentration.

Figure 19 shows the adsorption of plutonium(IV) polymer by commercial bone char in the presence of a low concentration of sodium citrate. At $\mathrm{pH}$ values higher than about 3 , citrate is: generally considered to be an excellent cation complexing agent. As the $\mathrm{pH}$ of a solution rises, citrate becomes an increasingly powerful complexing agent. A versatile complexing agent such as citrate can react with the bone char-waterplutonium system in more than one manner. It may associate with the particles of plutonium(IV) polymer, since citrate is an anion, while the particles of plutonium(IV) polymer may be cationic in nature. Such association may render the polymer particles neutral or anionic, and may interfere with the tendency of such particles to associate with phosphate compounds. Moreover, citrate easily complexes calcium ions, thus increasing 


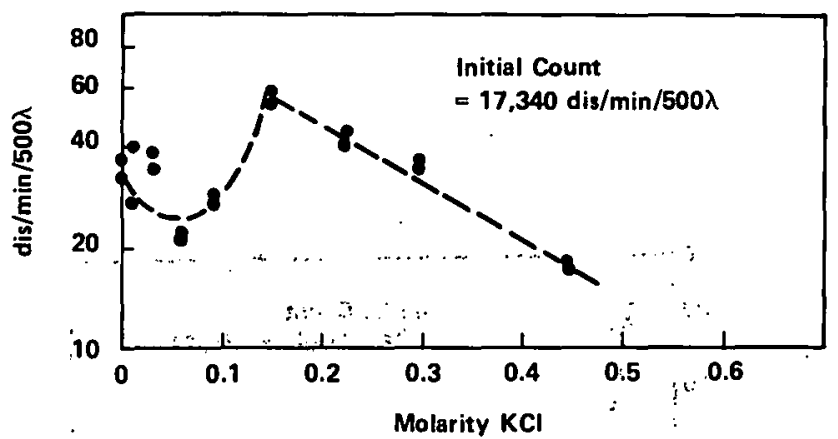

FIGURE 17 - Adsorption of plutonium(IV) polymer by bone char from solutions of potassium chloride (self-buffered).

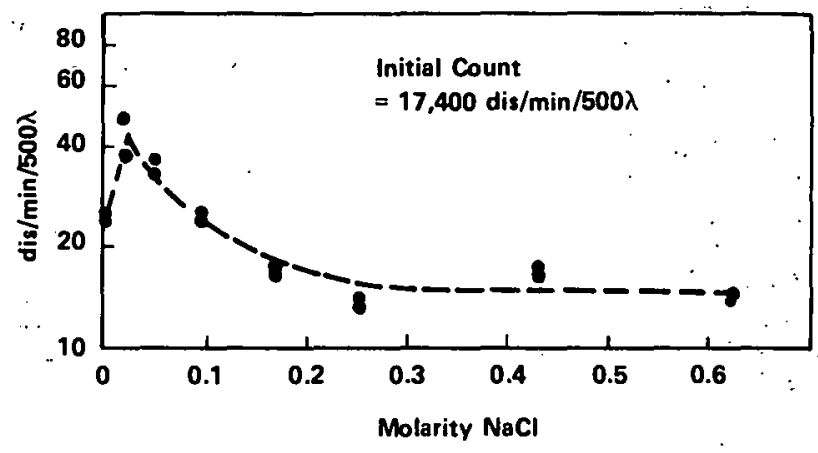

FIGURE 18 - Adsorption of plutonium(IV) polymer by bone chat from solutions of sodium chloride (self-buffered).

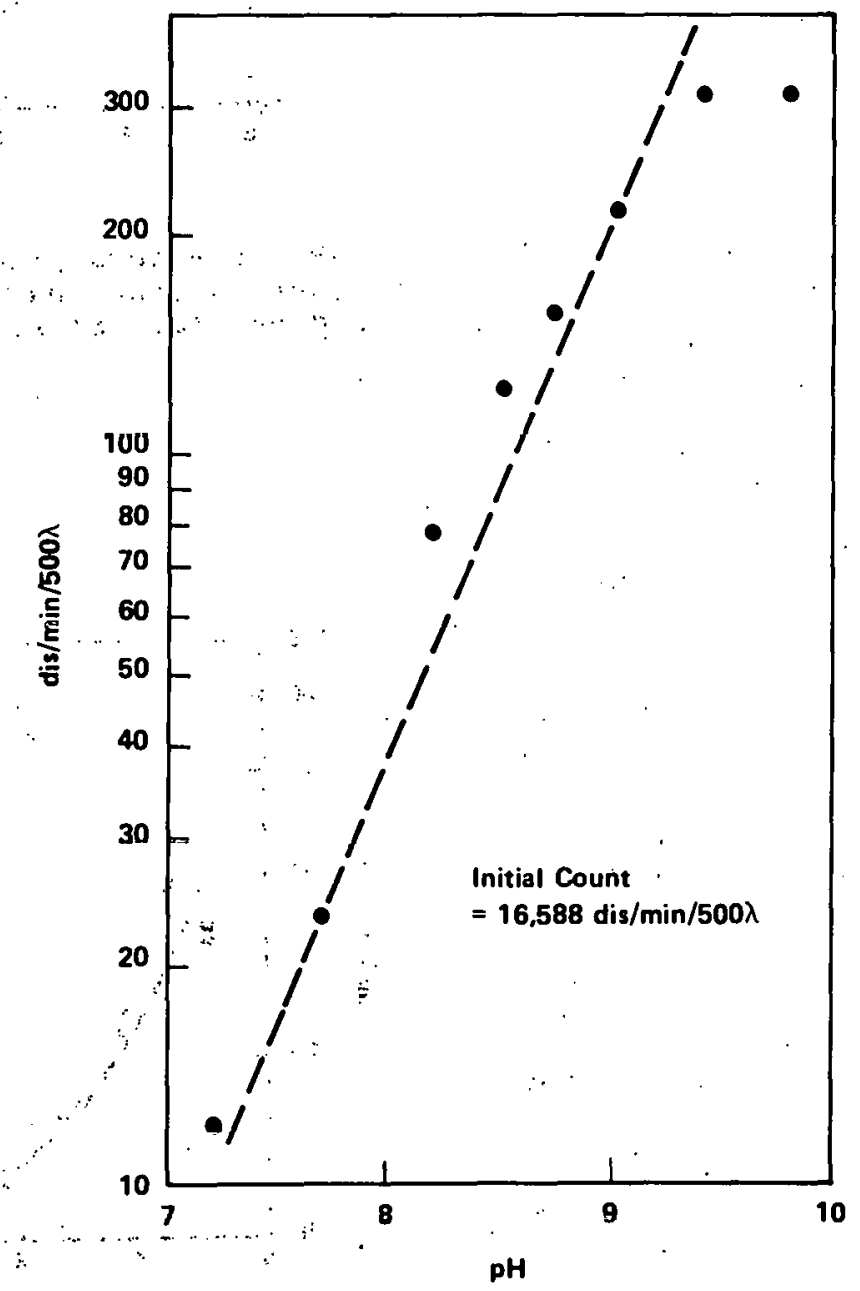

FIGURE I9 - Adsorption of plutonium(IV) polymer by bone char in the presence of $0.01 M$ citrate. 
the solubility of a substance such as hydroxyapatite. That citrate is deleterious to the adsorption of plutonium(IV) polymer by commercial bone char, and that this deleterious effect increases with increasing $\mathrm{pH}$, can be ascertained by examination of Figure 19. Whether this deleterious effect of citrate upon polymer adsorption by bone char is due primarily to reaction of the citrate with the polymer or with the bone char is not clear. Perhaps both effects are important.

Calcium chloride is currently used in some processes for the decontamination of radioactive waste water. The presence of calcium ion, an ion common to hydroxyapatite, may be expected to decrease the solubility of this material, and, since the phenomena of solubility and adsorption are primarily surface phenomena, to influence the adsorption of plutonium by bone char. The adsorption of plutonium (IV) polymer by bone char in the presence of calcium was therefore examined. This examination has led to the discovery of a curious effect which calcium has on the adsorption behavior of bone char. The presence of excess calcium ions in the bone char-water system appears to increase the $\mathrm{pH}$ of maximum plutonium (IV) polymer adsorption from about $\mathrm{pH} 7.3$ to a higher $\mathrm{pH}$ value. In the presence of $0.01 \mathrm{M}$ calcium, the $\mathrm{pH}$ of maximum polymer adsorption is about 9 . Figure 20 and 21 illustrate this effect. It may be observed that, while the $\mathrm{pH}$ of maximum adsorption is increased to about 9 by the presence of $0.01 \mathrm{M}$ calcium chloride, the extent of polymer does not appear to be appreciably affected by the presence of the calcium.

The observation that calcium affects the pH of maximum polymer adsorption suggests that phosphate ions, another species common to hydroxyapatite, may also affect the maximum adsorption $\mathrm{pH}$. This appears to be the case, as the $\mathrm{pH}$ of maximum adsorption of polymer by commercial bone char is increased by the presence of $0.01 \mathrm{M}$ phosphate in the bone charwater-polymer system. In this case, however, the pH shift.is less pronounced, i.e., the $\mathrm{pH}$ of maximum adsorption in the presence of $0.01 \mathrm{M}$ phosphate appears to be near 8. The origin or mechanisms of the common ion effect upon the adsorption of polymer by bone char is not known; but two illustrations of this effect are shown in Figures 22 and 23.

Portions of calcium chloride solution were added to $1-\mathrm{g}$ samples of bone char in $100 \mathrm{ml}$ of water containing a trace of

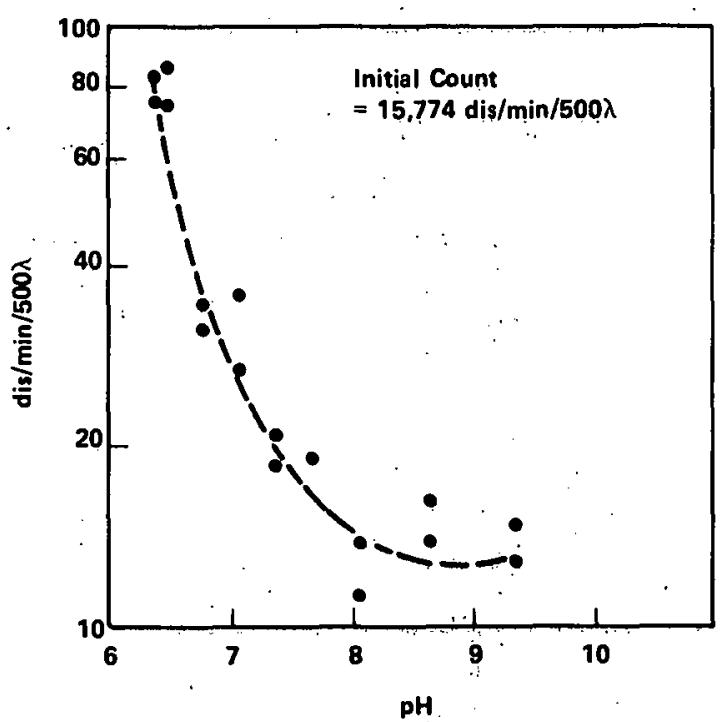

FIGURE 20 - Adsorption of plutonium(IV) polymer by bone char in the presence of 0.01M calcium chloride.

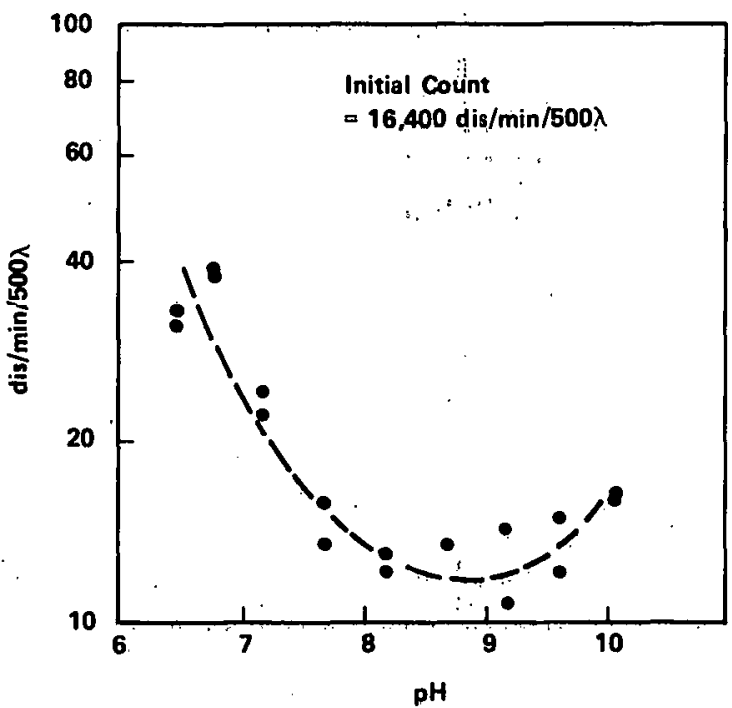

FIGURE 21 - Adsorption of plutonium(IV) polymer by bone char in the presence of $0.01 \underline{M}$ calcium chloride 


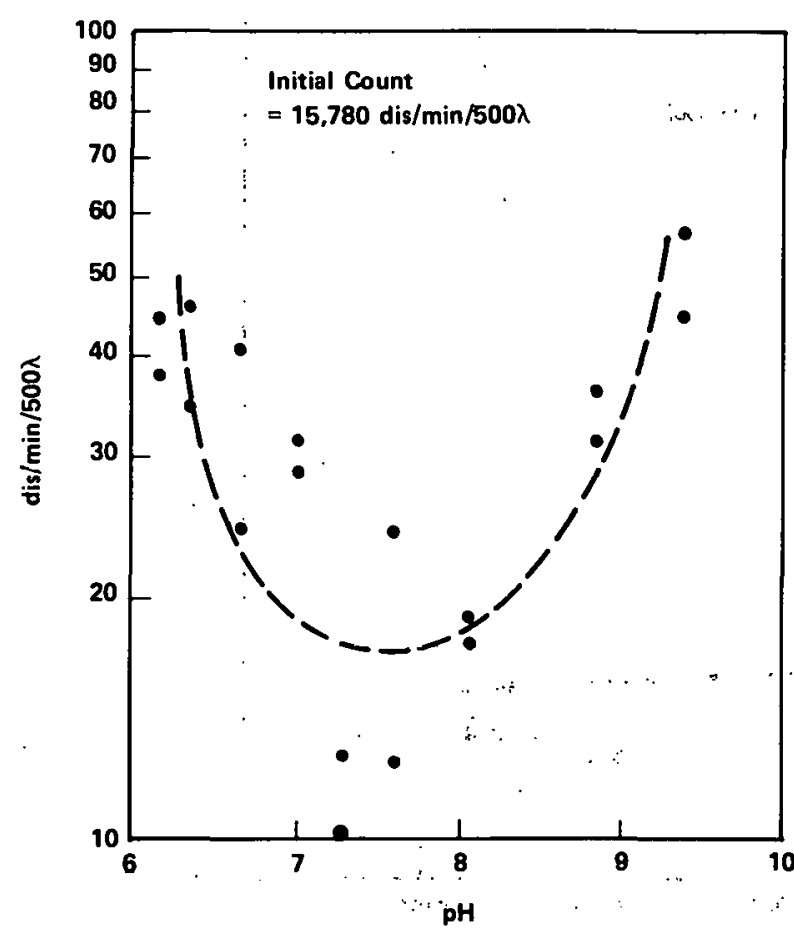

FIGURE 22 - Adsorption of plutonium(IV) polymer by bone char in the presence of $0.01 M$ phosphata.

plutonium(IV) polymer. It was not anticipated that the addition of the calcium would decrease the pH of the bone charwater system, although this did occur, as shown in Figures 24 and 25 . (Numbers on Figures 24 and 25 represent the measured $\mathrm{pH}$ values of the aqueous systems after equilibration for about one week.) What is more interesting, however, is that the adsorption of polymer by bone char in the presence of; excess calcium (unbuffered, as might occur in a calcium-bearing waste otroam passing throlugh a rolumn of bone char) appears to be maximized near $\mathrm{pH}$ 6.8 at a calcium concentration of about $0.02 \mathrm{M}$. Hence, the removal of polymeric plutonium(IV) by bone char depends upon both the $\mathrm{pH}$ and upon the calcium concentration.

Figure 26 indicates the adsorption of plutonium(IV) polymer by bone char in the presence of various calcium concentrations. A small amount of ethylenediamine hydrochloride was added to buffer the system. Although buffering was not perfect, as indicated by the slight progression of the solution $\mathrm{pH}$ with increasing. calcium concentration, a smali concentration of calcium appears to benefit the adsorption of plutonium by commercial bone char. This adsorption is probably not

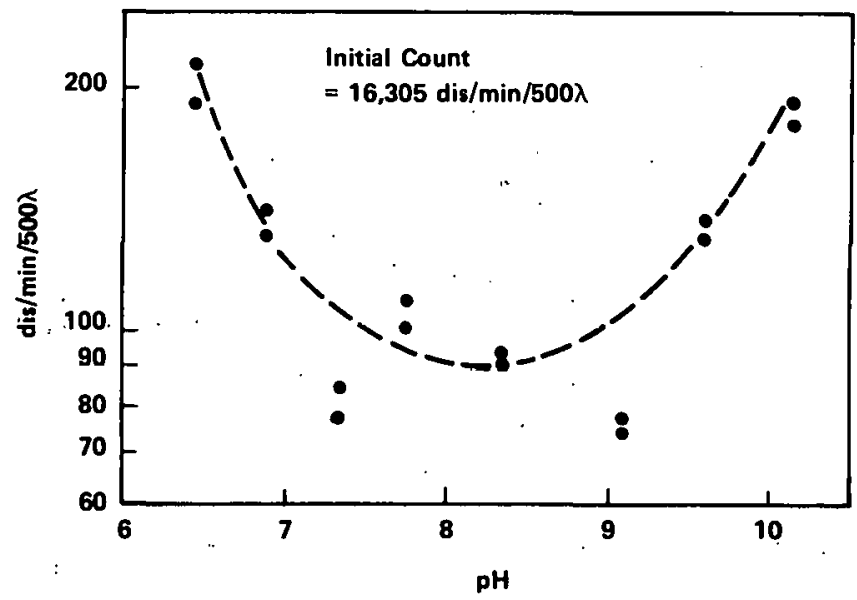

FIGURE 23 - Adsorption of plutonium(IV) polymer by bone char in the presence of $0.01 \mathrm{M} \mathrm{KH}_{2} \mathrm{PO}_{4}$.

linear with increasing calcium concentration above about $0.02 \mathrm{M}$ as indicated by Figure 26 , and the calcium concentration at maximum polymer adsorption remains to be determined.

ADSORPTION OF HEXAVALENT PLUTONIUM BY BONE CHAR AS A FUNCTION OF $\mathrm{pH}$

It has been demonstrated that a $\mathrm{pH}$ value near 7 maximizes the adsorption of plutonium(IV) polymer on bone char. It therefore seemed appropriate to examine the behavior of another plutonium oxidation state with samples of commercial bone char. Examination of a plutonium potential-pH diagram ${ }^{34,35}$ suggests that, after tetravalent plutonium polymer, some form of hexavalent or pentavalent plutonium may be the most likely form of soluble plutonium to occur in neutral or alkaline waste solutions. The adsorption behavior of hexavalent plutonium was examined in the same manner as used for studying the adsorption of plutonium (IV) polymer by samples of bone char. It was quickly apparent, however, that hexavalent plutonium behaved in a manner strikingly different from tetravalent plutonium. Six experiments revealed that this behavior is erratic and not subject 


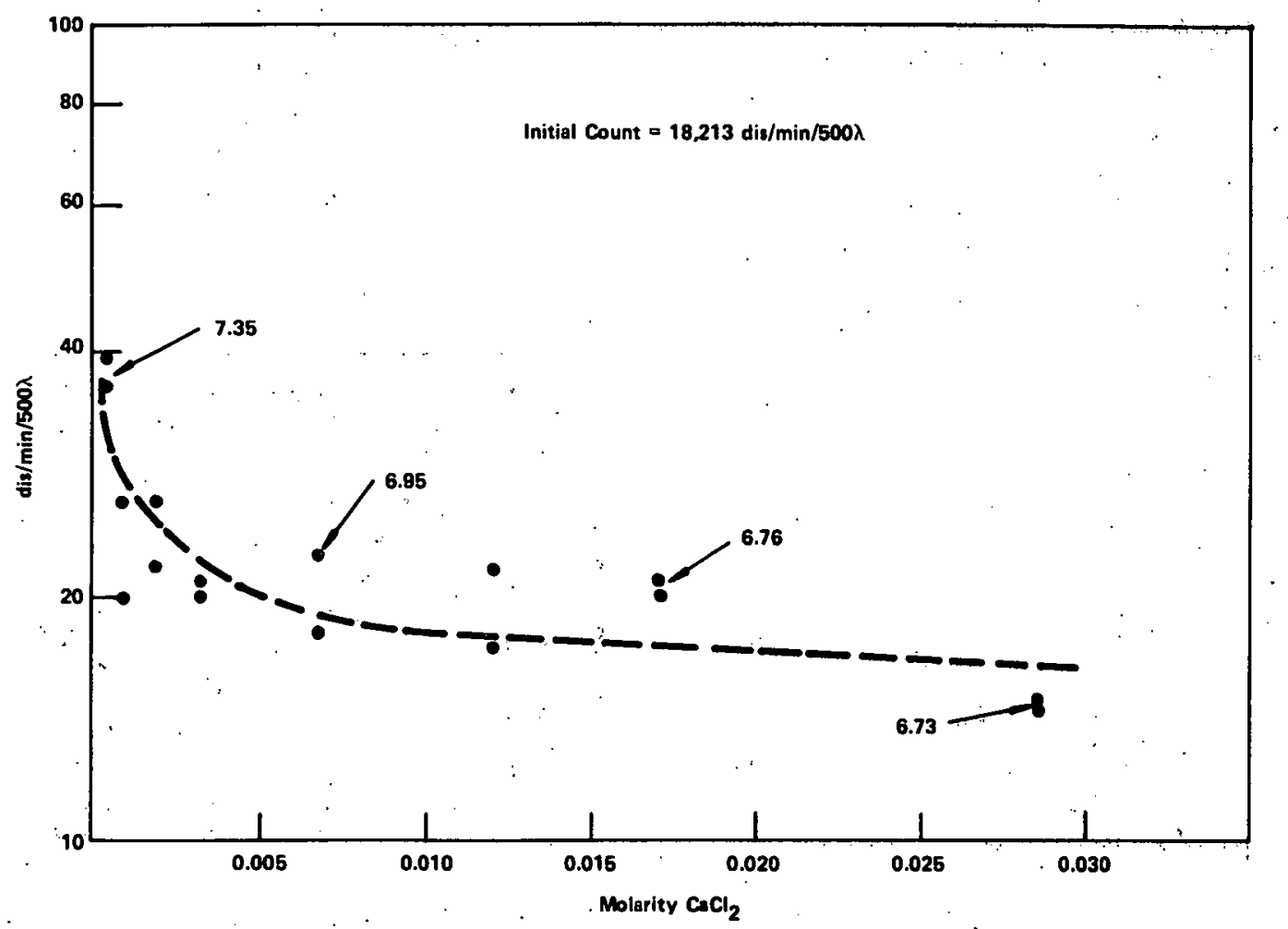

FIGURE 24 - Adsorption of plutonium(IV) polymer by bone char in the presence of excess calcium (numbers on plot are salution pH yalues).

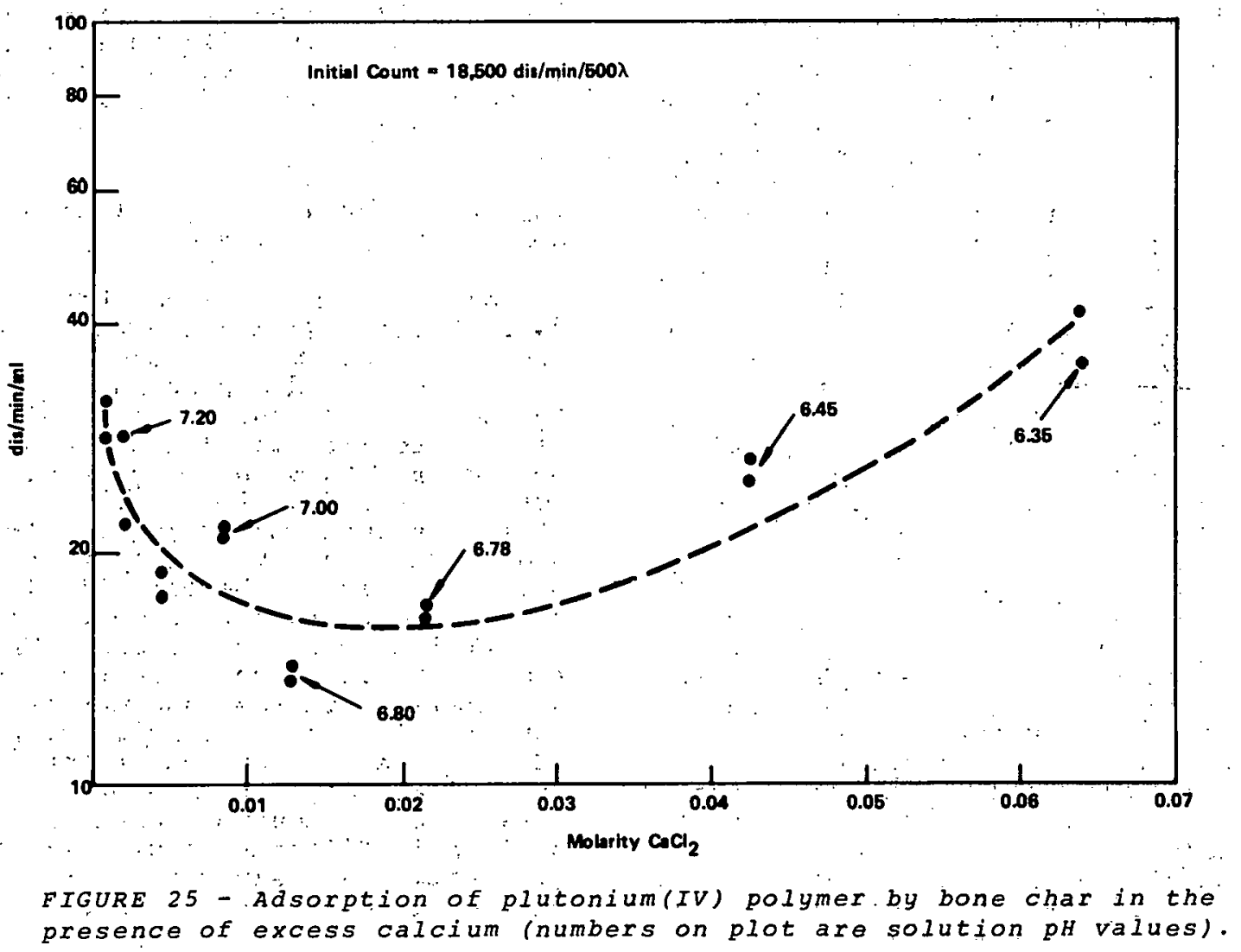




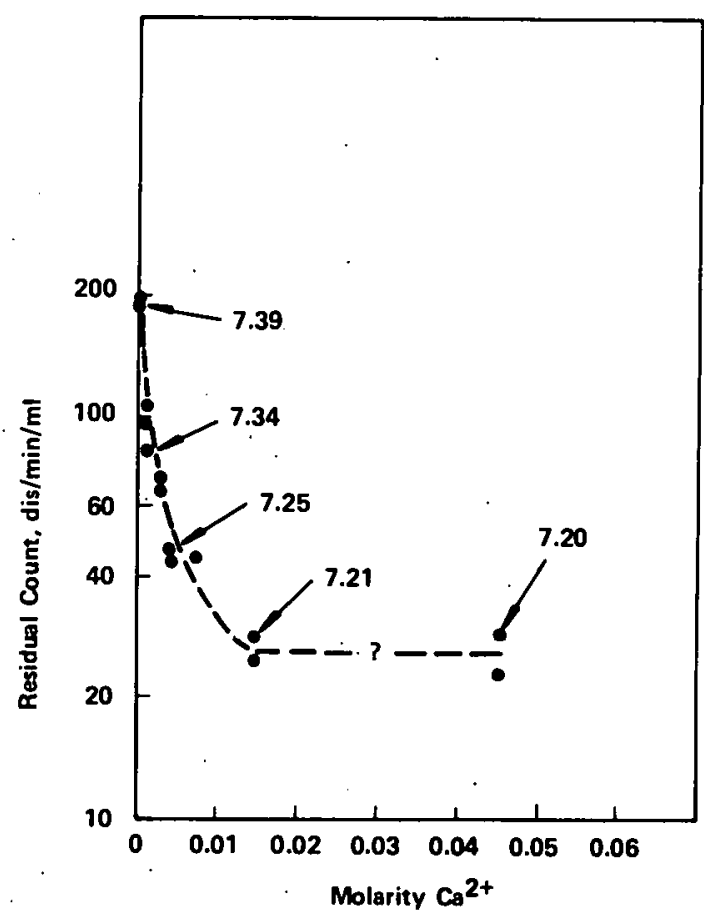

FIGURE 26 - Adsorption of plutonium polymer by.bone char in the presence of calcium (numbers on diagram are measured pH values).

to easy interpretation. Figure 27 shows the steady state count rate per minute of half ml samples of a solution of hexavalent plutonium that was allowed to equilibrate with bone char for about one week (Figures 27,28 and 29 each contain the results of two experiments). The data appear even more scattered that those data obtained from studies with plutonium(IV) polymer, and only suggest the possibility of a minimum count rate near pH 9. Solutions containing nigher in1tial concentrations of hexavalent plutonium also contained higher equilibrium concentrations of plutonium, in this manner they are similar to solutions of plutonium(IV) polymer. This appears to be the the only unambiguous conclusion that can be. drawn from Figures 27-29. In each experiment, a maximum in the adsorption of the plutonium near $\mathrm{pH} 9$ is suggested. maximum in the adsorption of plutonium corresponds to a minimum in the steady state count rate.) Unfortunately, this minimum cannot be unambiguously assigned because of the considerable, and surprising, scatter in the data. Figures 27 and 28 contain dashed lines which are drawn to illustrate the suggested minima in the plutonium concentration near $\mathrm{pH} 9$.

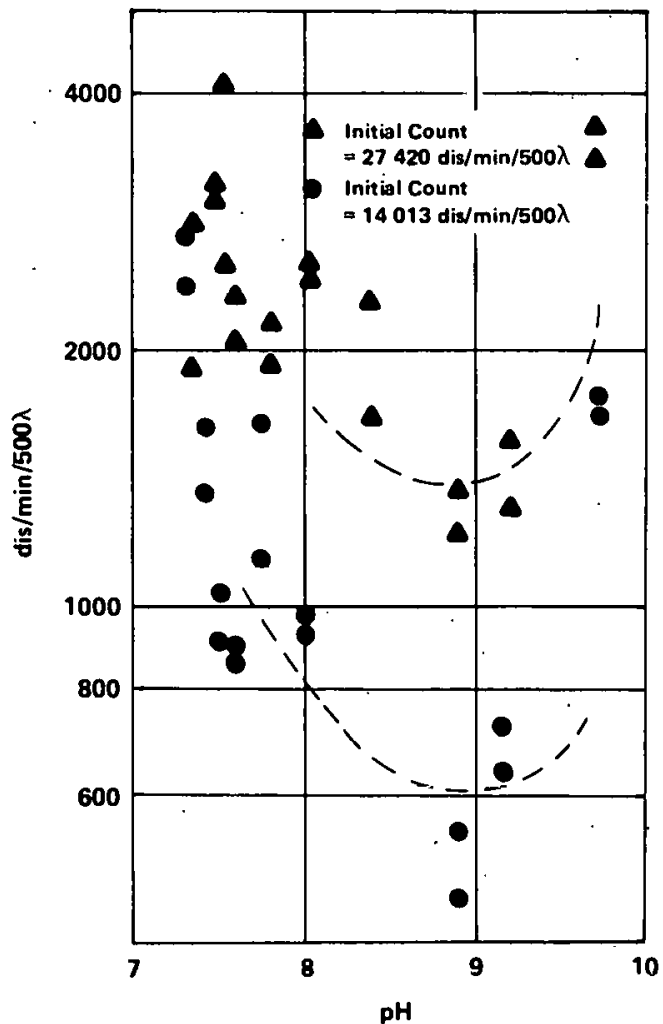

FIGURE 27 - Adsorption of hexavalent plutonium by bone char in ethylenediamine.= ammonia buffer.

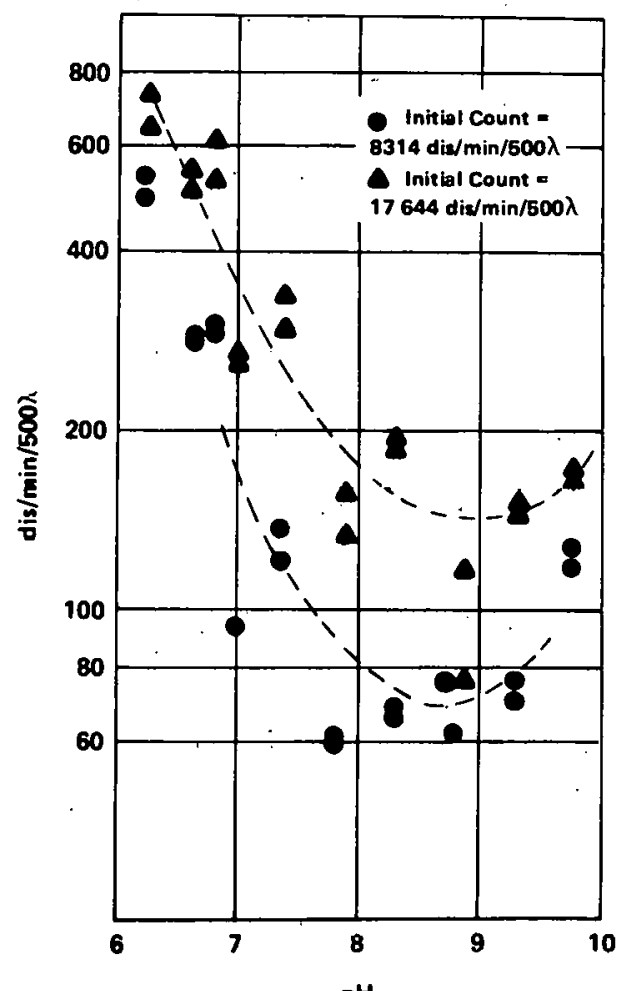

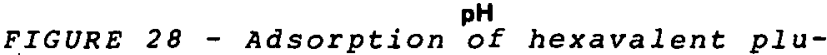
tonium by bone char in ethylenediamine ammonia buffer. 


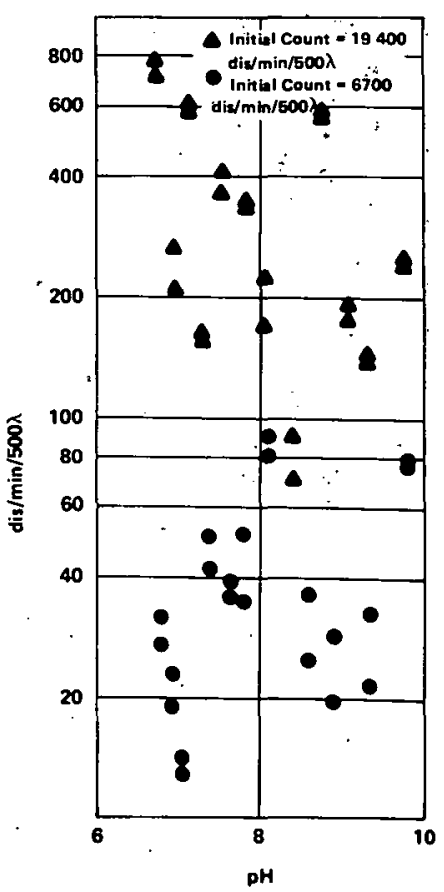

FIGURE 29 - Adsorption of hexavalent plutonium by bone char in ethylenediamine ammonia buffer.

These lines are visual aids drawn only to illustrate this suggested minimum. Figure 29 contains no such Iines because the data are too scattered to suggest this minimum unambiguously. Careful examination of Figures 27-29 also suggests the possibility of another adsorption maximum near $\mathrm{pH} 7$, but this possible maximum in the adsorption is not emphasized with dashed lines.

It is of interest, to speculate on the pronounced difference in the behavior of these two different oxidation states of plutonium. In comparison to hexavalent plutonium, the polymer is relatively "inert"; that is, many reactions of the polymer, such as depolymerization to $\mathrm{Pu}^{4} 7$ cations, oxidation, or reduction, are generally slow except under extreme conditions. The polymer, so far as is known, forms no "complexes" such as might be formed by simple plutonium cations. Hexavalent plutonium, in contrast, forms a wide variety of complexes, and is quite reactive as an oxidizing agent. That is, there are many circumstances under which hexavalent plutonium is subject to facile reduction to the pentavalent, . tetravalent, or trivalent oxidation states.
The general problem of the equilibrium distribution of valence states of plutonium may be solved in terms of the plutonium ion alpha coefficients and two other variables such as solution $\mathrm{pH}$ and redox potential. The potential behavior of solutions in contact with bone char has been examined above. Although nothing is known about the plutonium alpha coefficients which are appropriate for the bone char-water system, it may nevertheless be instructive to examine the behavior of valence state distributions at the pH and potential values of such systems assuming no complexation. Computations can be made that yield a model of the equilibrium valence state distribution of the uncomplexed plutonium as well as the molar concentration of all of the soluble plutonium.

The equilibrium valence state distribution of plutonium (neglecting complexation), as well as the total molar solubility of the plutonium, in a solution of $\mathrm{pH} 7$ at selected values of the oxidation potential of the solution is shown in Table 3. Table 4 shows the plutonium valence state distribution, and the total molar solubility of the plutonium for a solution at $\mathrm{pH} 9$ for selected values of the solution oxidation potential. It may be seen from Tables 3 and 4 that pentavalent plutonium is the species which is predominant throughout most of the potential values typical of the bone char-water system at $\mathrm{pH} 7$, and always the predominant species at $\mathrm{pH} 9$ for similar potential values. These tables, of course, neglect all complexation of the various plutonium ions as well as the hydrolysis of plutonium species with the exception of $\mathrm{PuOH}^{3+}$. Complexation of the various plutonium ions in the bone char-water system is no doubt very important, but it is not considered in Tables 3 and 4 because there is no information on the nature of the complexes, especially the complexes with orgaric material derived from partially decomposed bone marrow, which may be formed by the plutonium in the bone char-water system in neutral or mildly alkaline circumstances. Tables 3 and 4 also indicate that large concentrations of hexavalent plutonium, such as introduced to the bone char-water system for equilibrium studies, may be easily reduced. This reduction, as indicated by the values for the equilibrium molar solubility of the plutonium, yields concentrations less than initial concentrations of plutonium used in the equilibration experiments, so that the reduction of hexavalent plutonium by bone char results primarily in hydrous plutonium(IV). oxide particles, i.e., polymeric plutonium(IV). 
Table 3

VALENCE STATE DISTRIBUTION AND TOTAL SOLUBLE PLUTONIUM (M) AS A FUNCTION OF SOLUTION POTENTIAL (EMF) AT PH 7

(Complexation neglected; $\mathrm{K}_{\mathrm{sp}}$ of $\mathrm{Pu}(\mathrm{OH})_{4}$ taken as $10^{-56}$.)

\begin{tabular}{|c|c|c|c|c|c|}
\hline EMF & Plutonium (III) & Plutonium (IV) & Plutonium (V) & Plutonium (VI) & $\begin{array}{c}\text { Total } \\
\text { Plutonium } \\
\end{array}$ \\
\hline $\begin{array}{l}0.100 \mathrm{E}+00 \\
0.140 \mathrm{E}+00 \\
0.180 \mathrm{E}+00 \\
0.220 \mathrm{E}+00 \\
0.260 \mathrm{E}+00 \\
0.300 \mathrm{E}+00 \\
0.340 \mathrm{E}+00 \\
0.380 \mathrm{E}+00 \\
0.420 \mathrm{E}+00 \\
0.460 \mathrm{E}+00 \\
0.500 \mathrm{E}+00\end{array}$ & $\begin{array}{l}1.000 \mathrm{E}+00 \\
1.000 \mathrm{E}+00 \\
0.995 \mathrm{E}+00 \\
0.897 \mathrm{E}+00 \\
0.279 \mathrm{E}+00 \\
0.169 \mathrm{E}-01 \\
0.765 \mathrm{E}-0.3 \\
0.340 \mathrm{E}-04 \\
0.151 \mathrm{E}-05 \\
0.672 \mathrm{E}-07 \\
0.299 \mathrm{E}-08\end{array}$ & $\begin{array}{l}0.360 \mathrm{E}-09 \\
0.171 \mathrm{E}-08 \\
0.807 \mathrm{E}-08 \\
0.345 \mathrm{E}-07 \\
0.510 \mathrm{E}-07 \\
0.147 \mathrm{E}-07 \\
0.314 \mathrm{E}-08 \\
0.663 \mathrm{E}-0.9 \\
0.140 \mathrm{E}-09 \\
0.295 \mathrm{E}-10 \\
0.621 \mathrm{E}-11\end{array}$ & $\begin{array}{l}0.101 \mathrm{E}-04 \\
0.226 \mathrm{E}-03 \\
0.507 \mathrm{E}-02 \\
0.103 \mathrm{E}+00 \\
0.721 \mathrm{E}+00 \\
0.983 \mathrm{E}+00 \\
0.999 \mathrm{E}+00 \\
1.000 \mathrm{E}+00 \\
1.000 \mathrm{E}+00 \\
0.100 \mathrm{E}+01 \\
0.100 \mathrm{E}+01\end{array}$ & $\begin{array}{l}0.159 \mathrm{E}-18 \\
0.170 \mathrm{E}-16 \\
0.181 \mathrm{E}-14 \\
0.174 \mathrm{E}-12 \\
0.571 \mathrm{E}-11 \\
0.374 \mathrm{E}-10 \\
0.181 \mathrm{E}-09 \\
0.857 \mathrm{E}-09 \\
0.407 \mathrm{E}-08 \\
0.193 \mathrm{E}-07 \\
0.915 \mathrm{E}-07\end{array}$ & $\begin{array}{l}0.833 \mathrm{E}-13 \\
0.176 \mathrm{E}-13 \\
0.372 \mathrm{E}-14 \\
0.869 \mathrm{E}-15 \\
0.588 \mathrm{E}-15 \\
0.205 \mathrm{E}-14 \\
0.955 \mathrm{E}-14 \\
0.453 \mathrm{E}-13 \\
0.215 \mathrm{E}-12 \\
0.102 \mathrm{E}-11 \\
0.483 \mathrm{E}-11\end{array}$ \\
\hline
\end{tabular}

Table 4

VALENCE STATE DISTRIBUTION AND TOTAL SOLUBLE PLUTONIUM (M). AS A FUNCTION OF SOLUTION POTENTIAL (EMF) AT pH 9

(Complexation neglected; $K_{s p}$ of $\mathrm{Pu}(\mathrm{OH})_{4}$ taken as $10^{-.56}$.)

\begin{tabular}{|c|c|c|c|c|c|}
\hline EMF & Plutonium (III) & Plutonium (IV) & Plutonium (V) & Plutonium (VI) & $\begin{array}{l}\text { Total } \\
\text { Plutonium }\end{array}$ \\
\hline $\begin{array}{l}0.100 \mathrm{E}+00 \\
0.140 \mathrm{E}+00 \\
0.180 \mathrm{E}+00 \\
0.220 \mathrm{E}+00 \\
0.260 \mathrm{E}+00 \\
0.300 \mathrm{E}+00 \\
0.340 \mathrm{E}+00 \\
0.380 \mathrm{E}+00 \\
0.420 \mathrm{E}+00 \\
0.460 \mathrm{E}+00 \\
0.500 \mathrm{E}+00\end{array}$ & $\begin{array}{l}0.994 \mathrm{E}-03 \\
0.442 \mathrm{E}-04 \\
0.196 \mathrm{E}-05 \\
0.873 \mathrm{E}-07 \\
0.388 \mathrm{E}-08 \\
0.172 \mathrm{E}-09 \\
0.7 .66 \mathrm{E}-11 \\
0.340 \mathrm{E}-12 \\
0.151 \mathrm{E}-13 \\
0.672 \mathrm{E}-15 \\
0.299 \mathrm{E}-16\end{array}$ & $\begin{array}{l}0.358 \mathrm{E}-10 \\
0.755 \mathrm{E}-11 \\
0.159 \mathrm{E}-11 \\
0.336 \mathrm{E}-12 \\
0.708 \mathrm{E}-13 \\
0.149 \mathrm{E}-13 \\
0.314 \mathrm{E}-14 \\
0.663 \mathrm{E}-15 \\
0.140 \mathrm{E}-15 \\
0.295 \mathrm{E}-16 \\
0.621 \mathrm{E}-17\end{array}$ & $\begin{array}{l}0.999 E+00 \\
1.000 E+00 \\
1.000 E+00 \\
0.100 E+01 \\
0.100 E+01 \\
0.100 E+01 \\
0.100 E+01 \\
0.100 E+01 \\
0.100 E+01 \\
0.100 E+01 \\
0.100 E+01\end{array}$ & $\begin{array}{l}0.158 \mathrm{E}-13 \\
0.752 \mathrm{E}-13 \\
0.357 \mathrm{E}-12 \\
0.169 \mathrm{E}-11 \\
0.803 \mathrm{E}-11 \\
0.381 \mathrm{E}-10 \\
0.181 \mathrm{E}-09 \\
0.857 \mathrm{E}-09 \\
0.407 \mathrm{E}-08 \\
0.193 \mathrm{E}-07 \\
0.915 \mathrm{E}-07\end{array}$ & $\begin{array}{l}0.838 \mathrm{E}-18 \\
0.397 \mathrm{E}-17 \\
0.188 \mathrm{E}-16 \\
0.894 \mathrm{E}-16 \\
0.424 \mathrm{E}-15 \\
0.201 \mathrm{E}-14 \\
0.954 \mathrm{E}-14 \\
0.453 \mathrm{E}-13 \\
0.215 \mathrm{E}-12 \\
0.102 \mathrm{E}-11 \\
0.483 \mathrm{E}-11\end{array}$ \\
\hline
\end{tabular}

At the higher EMF values, where plutonium (V) predominates, the solubility of the plutonium is approximately independent of acidity:

$$
\mathrm{Pu}(\mathrm{OH})_{4}=\text { PuOt }+2 \mathrm{HOH}+\varepsilon
$$

Typically, the initial concentration of the plutonium in bone char experiments is about 20,000 dis/min $/ 500 \lambda$. Also, the final concentration is about $20 \mathrm{dis} / \mathrm{min} /$ $500 \lambda$. Thus the final steady state concentration is not likely to be more than about $3 E-12 M$, which is a value that approximates those solubility values calculated in Tables 3 and 4 for various conditions of $\mathrm{pH}$ and potential. What is more interesting, however, is the observation that calculation suggests the equilibrium concentration of soluble plutonium to be much less than the initial concentration; and that this reduction in solubility occurs through the formation of plutonium(IV)

polymer. Hence, in the bone char-water system, most of the initial plutonium(VI) is reduced to polymer. But the nature of plutonium polymer is highly dependent upon the conditions of formation, at least in experimental systems studied so far, and there is no reason to suppose that the properties of the polymer (such as size, charge, molecular weight, and degree of hydration) prepared by bone char reduction should not also depend upon the particulars of the reducing environment, such as potential and $\mathrm{pH}$. Measurement of the adsorption of hexavalent plutonium upon bone char thus represents the measurement of more than one phenomenon: the intrinsic adsorption behavior of hexavalent plutonium on bone char, the intrinsic behavior of pentavalent plutonium upon bone char, the intrinsic behavior of the adsorption of complexes of plutonium(V) and plutonium(VI), and the intrinsic behavior of plutonium(IV) polymer upon bone char. 
It seems very likely that the last parameter is a function of the type of colloidal polymeric particles produced, and is thus a function of potential, pH, and perhaps, ionic strength.

Hexavalent plutonium prepared as described on page 10 does not appear to be strongly adsorbed by glass. During the course of a month, a solution at $\mathrm{pH} 6.60$ (containing originally 13,111 dis/min/ $500 \lambda)$ decreased at most to $12,740 \mathrm{dis} /$ $\mathrm{min} / 500 \lambda$. Similar behavior was shown by solutions of $\mathrm{pH} 6.90,7.20,7.67,8.05$, 8.52, and 8.92. Since \pm 2 standard deviations in this count rate is about $\pm 230 \mathrm{dis} / \mathrm{min}$, this represents little adsorption. However, solutions of plutonium(VI) at $\mathrm{pH}$ values of $9.23,9.58$, and 9.92 showed slightly more adsorption.

\section{Adsorption Isotherms of Bone Char with Uranium and Plutonium}

THE NATURE OF ADSORPTION ISOTHERMS REPRESENTING THE LOADING OF BONE CHAR WITH URANIUM AND PLUTONIUM

At a given temperature and $\mathrm{pH}$, the adsorption isotherm is the relationship between the amount of a substance adsorbed by a substrate and the concentration of the unadsorbed substance in the surrounding solution. For a radioactive isotope adsorption isotherm, the residual activity in the aqueous solution is usually plotted as abscissa, and the activity adsorbed per gram of substrate as ordinate. The line connecting points plotted in this manner is called the adsorption isotherm, and the ordinate of any point on the isotherm is the adsorptive capacity of the substrate for the dissolved substance. For use in characterizing the behavior of very dilute radioisotopes, it is common to plot the coordinates of the adsorption isotherm on logarithmic scales, as this treatment usually yields an isotherm which is well approximated by a straight line. Of several possible isotherm equations, one of the most useful is the Freundich equation which relates the concentration of the unadsorbed substance with remains dissolved in the solution to the amount of substance adsorbed per unit weight of substrate. The Freundich isotherm is given in Equation 6:

$$
\mathrm{x} / \mathrm{m}=\mathrm{kCl} \mathbf{n}
$$

where, in the case of radioisotopes,

$$
\begin{aligned}
\mathbf{x}= & \text { amount of activity adsorbed } \\
\mathrm{m}= & \text { weight of bone char } \\
\mathrm{c}= & \text { concentration of unadsorbed } \\
& \text { activity which remains in } \\
& \text { solution. }
\end{aligned}
$$

" $k$ " and " $n$ " are constants characteristic of the particular adsorption system. In logarithmic form, the isotherm equation may be rewritten as

$$
\log (x / m)=\log (k)+(1 / n)(\log (C)
$$

in which $(1 / n)$ represents the slope of portions of Equation 7 which are well approximated by a straight line. From the study of adsorption isotherms, it can often be determined whether a desired degree of decontamination of radioactive liquids can be effected by adsorption alone. Adsorption isotherms may also be used to study the effects of $\mathrm{pH}$ and temperature on the adsorption of radioisotopes. Ideally, adsorption isotherms plotted in the manner of Equation 7 are straight lines, but real adsorption systems frequently deviate from this ideal. Data sets which contain intrinsic scatter may be fitted to the form of Equation 7 by techniques such as the method of least squares. The preparation of useful adsorption isotherm usually requires strict attention to experimental details.

The performance of a solid sorption agent in treating a liquid depends upon four factors: stoichiometric capacity of the solid, equilibrium behavior (a factor which limits the attainment of complete stoichiometric loading), kinetics of adsorption (a slow rate of adsorption is deleterious to optimizing the performance of an adsorption system), and process arrangement. It sometimes happens that the realizable adsorption capacity of an adsorbent has a value which is nearly constant in many different situations. In other cases, the effective capacity of the adsorbent varies with solute concentration, and must be determined from the equilibrium behavior of the adsorbent under various circumstances.

The adsorption isotherm intercept (the value of " $\mathrm{k}$ ") is an approximate indicator of sorption capacity, and the isotherm slope, $1 / n$, of adsorption affinity. Experimental adsorption data often follows the Freundich equation over moderate ranges of concentration. The Freundlich equation does not reduce to a linear adsorption expression at very low concentrations of adsorbing species as does the Langmuir isotherm, nor does it agree well with the Langmuir equation at high concentrations, since " $n$ " must reach some 
limiting value when the surface of the adsorbent is fully covered. Generally, " $k$ " and " $n$ " decrease with increasing complexity of the waste water. High values of " $k$ " and " $n$ " indicate high adsorption throughout the concentration range studied; conversely, low values of these parameters indicate low adsorption. A low value of " $n$ " (the slope of the isotherm, $1 / n$, has a high value), indicates high adsorption of the solute at high solute concentrations and poor adsorption of the solute at low. solute concentrations.

PROCEDURES USED IN THE DETERMINATION OF ADSORPTION ISOTHERMS

Samples of commercial bone char were ground until the average size of the bone char particles was less than 75 microns. Samples of this bone char were weighed and transferred to volumetric flasks containing $100 \mathrm{ml}$ of a buffered solution. Buffering agents used were ammonia and acetate salts in order to keep the $\mathrm{pH}$ between 7 and 10. The radioisotope solutions initially contained 20,000-50,000 dis/min/mI alpha activity. Some radioactivity adsorbed onto the walls of the glass volumetric flasks. However, correction was made for this by running a blank flask (or control flask) with each experiment. Adsorption onto glass walls of the volumetric flasks was affected by solution $\mathrm{pH}$ and the valence state of the radioisotope. Flasks were shaken for 72 hours with a mechanical shaker. After this time, samples were taken from the flasks, which also contained variable amounts of bone char. and counted for alpha activity using a scintillation counter.

The uranium used in these experiments was either uranium- 233 or urantum -234 . The uranium-234 also contained $0.37 \%$ uranium- 232 as well as trace quantities of radium-224, radon-220, thorium-228, and plutonium-239. The uranium-233 contained 99.638 uranium-233, 0.338 uranium-234, 0.048 uranium-238 and a trace of thorium232. The plutônium-238 contained 79.98 plutonium-238, with the balance of the plutonium present as other isotopes,: principally plutonium-239. The plutonium(VI) was prepared by a standard technique described earlier (page 10), while the plutonium(IV) polymer was a portion of the polymer prepared by peptization of tetravalent plutonium hydroxide described earlier (page 10.).

\section{ADSORPTION OF URANIUM BY BONE CHAR}

Experiments were performed to determine the change in the adsorption effectiveness of bone char. with respect to uranium as a function of $\mathrm{pH}$. Since bone char tends to be slightly soluble at $\mathrm{pH}$ values below 7, the pH values chosen were 10,8 , and 7. The various isotherms generated are shown in Figures 30,31 , and 32 . The isotherm at $\mathrm{pH} 10$ was run with uranium-234; whereas the isotherms at pH 8 and 7 were run using uranium-233.

In order to compare the various results, the data at $\mathrm{pH} 10$ (using uranium-234) was normalized to uranium-233 data by multiplying the data by the ratios of their respective half-lives (Figure 33 ).

$$
\begin{aligned}
& \mathrm{dis} / \mathrm{min} / \mathrm{ml}{ }^{23}{ }^{4} \mathrm{U} \times \frac{2.47 \times 10^{5} \mathrm{yr}}{1.59 \times 10^{5} \mathrm{Yr}} \\
& =\mathrm{dis} / \mathrm{min} / \mathrm{ml}{ }^{2{ }^{3}{ }^{3} \mathrm{U}}
\end{aligned}
$$

The following isotherm equations

$$
\begin{aligned}
& \mathrm{pH} 7: \frac{\mathrm{x}}{\mathrm{m}}=6 \times 10^{-2} \mathrm{c}^{2.09} \\
& \mathrm{pH} 8: \frac{\mathrm{x}}{\mathrm{m}}=6.1 \mathrm{C}^{1.45} \\
& \mathrm{pH} 10: \frac{\mathrm{x}}{\mathrm{m}}=18.6 \mathrm{c}^{1.21}{\underset{\text { (normalized to }}{\text { uranium-233) }}}^{\text {(nom }}
\end{aligned}
$$

were derived by fitting the Freundlich equation (Equation 6 ) to the data.

It can be seen from Figures 30-33 that $\mathrm{pH} 10$ treatment is better for a batchtype operation since the capacity is greater at equilibrium effluent concentrations. Treatment at $\mathrm{pH} 7$ is better for bone char-column operation since the capacity is greater in equilibrium with a typical influent at column exhaustion. Treatment at $\mathrm{pH} 8$ falls in between the $\mathrm{pH} 7$ and $\mathrm{pH} 10$ treatments. Bone char at $\mathrm{pH} 10$ has a higher adsorption capacity, at low concentrations, than at $\mathrm{pH} 8$ and $\mathrm{pH} 7$. However, at high concentrations: the adsorption capacity is highest at $\mathrm{pH} 7$. Also, the adsorption affinity is much higher at $\mathrm{pH} 7$ than at $\mathrm{pH} 8$ and $\mathrm{pH} 10$.

In order to make farther comparisons between the $\mathrm{pH} 7, \mathrm{pH} 8$, and $\mathrm{pH} 10$ adsorption characteristics of bone char, the various equilibrium distribution coefficients, $K_{d}$, were determined using the three fitted Freundlich equations 


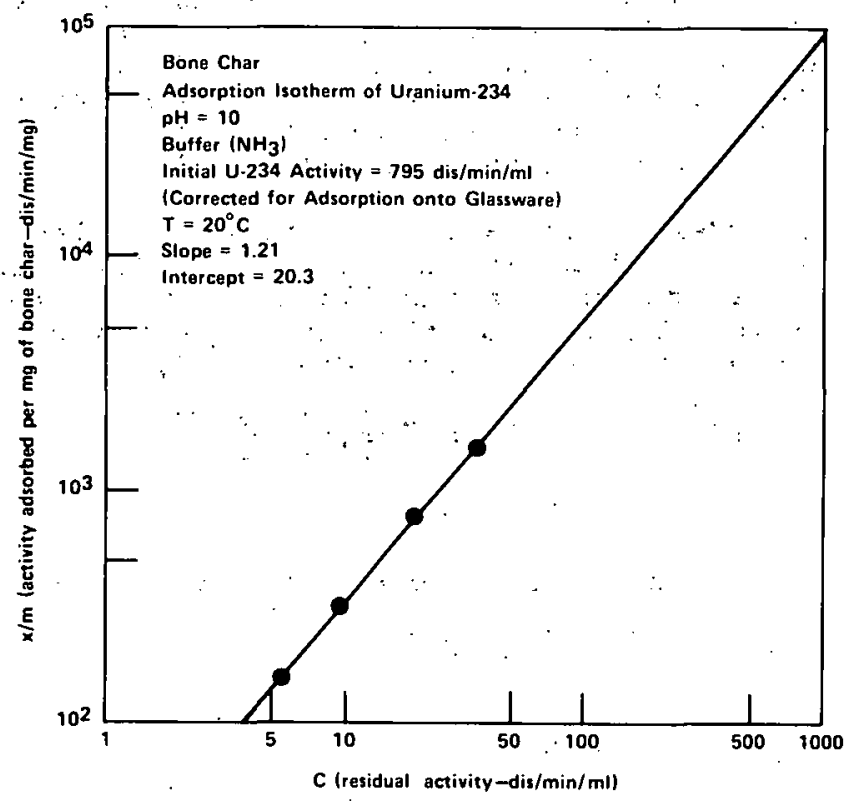

FIGURE 30 - Adsorption of uranium onto bone char at pH 10 .

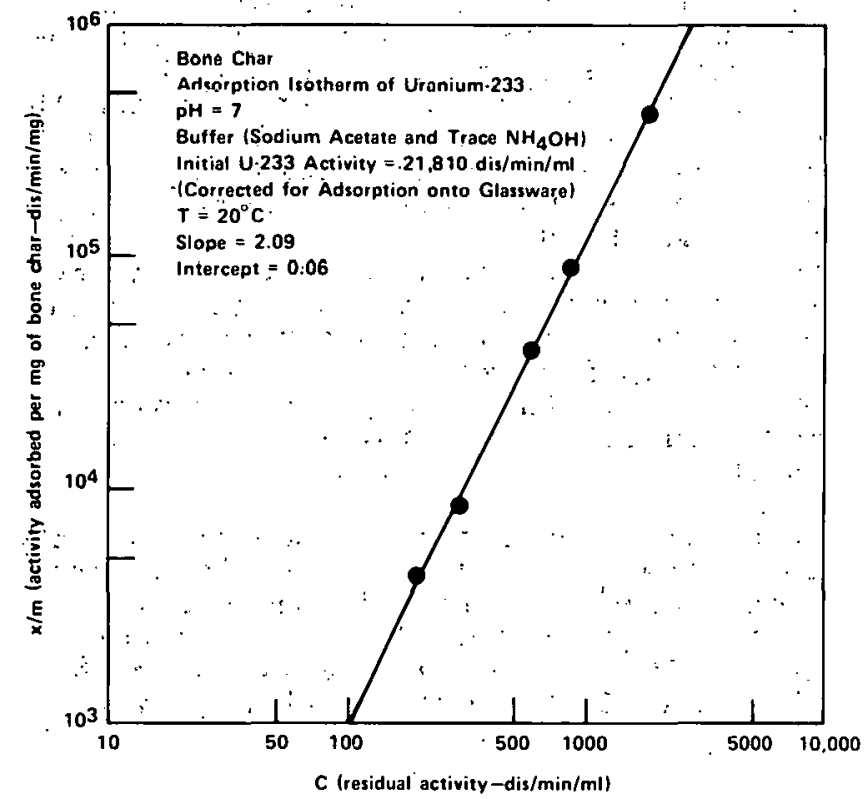

FIGURE 32 - Adsorption of uranium onto bone char at $p H 7$.

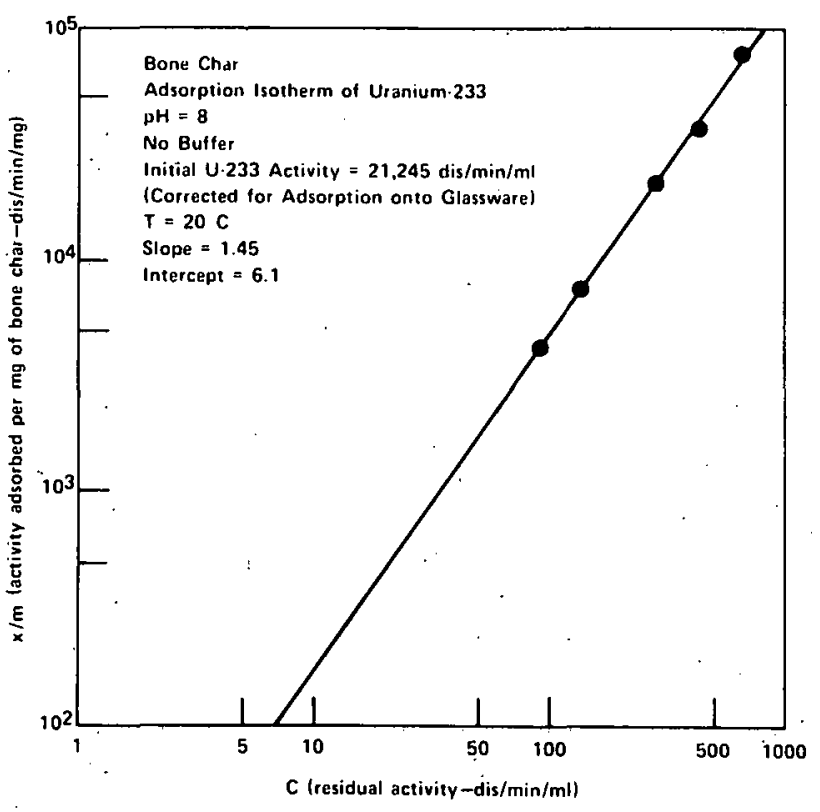

FIGURE 31 - Adsorption of uranium onto bone char at $p H 8$.

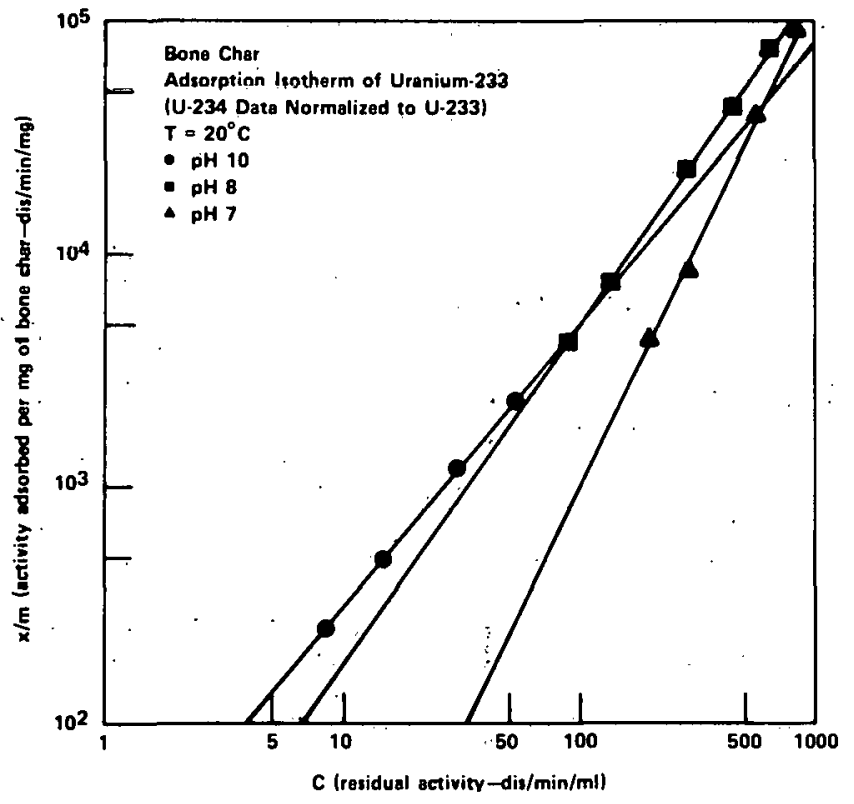

FIGURE 33 - Comparison of adsorption of uranium onto bone char àt various $p H$ values. 
(that is, extrapolated from data). The $K_{d}$ values are defined as follows:

$$
\begin{aligned}
& \mathrm{K}_{\mathrm{d}}= \begin{array}{l}
\text { Concentration of }{ }^{2{ }^{3} \mathrm{U}} \\
\text { adsorbed onto bone char } \\
\text { Concentration residual } \\
\text { activity }\left({ }^{2} \cdot{ }^{3} \mathrm{U}\right) \text { in liquid }
\end{array} \\
& \mathrm{K}_{\mathrm{d}}=\frac{\mathrm{x} / \mathrm{m}}{\mathrm{C}}
\end{aligned}
$$

The values of concentrations used in the extrapolations ranged from. 1 to 500 $\mathrm{dis} / \mathrm{min} / \mathrm{ml}$ uranium-233, which is equivalent to $2.25 \times 10^{-10}$ gram mole/liter to. 1.l. $\times 10^{-7}$ gram mole/liter. The $\mathrm{K}_{\mathrm{d}}$ values were then plotted versus residual concentration (that is, the concentration in equilibrium with the bone char) of uranium to determine the effect of $\mathrm{pH}$ on the distribution coefficients (see Figures 34 and 35). As can be seer, the steepest slope occürs at $\mathrm{pH} 7$. At low values of $c$; higher $k_{d}$ values occur at pH 10 . Figure 33 is similar to Figure 32 . However, it is easier to visualize the behavior of uranium when one looks at Figures 34 and 35 . Two possible mechanisms could cause this behavior. The first possible mechanism is that of polymer formation, since uranium may have the following forms in alkaline or neutral solutions:

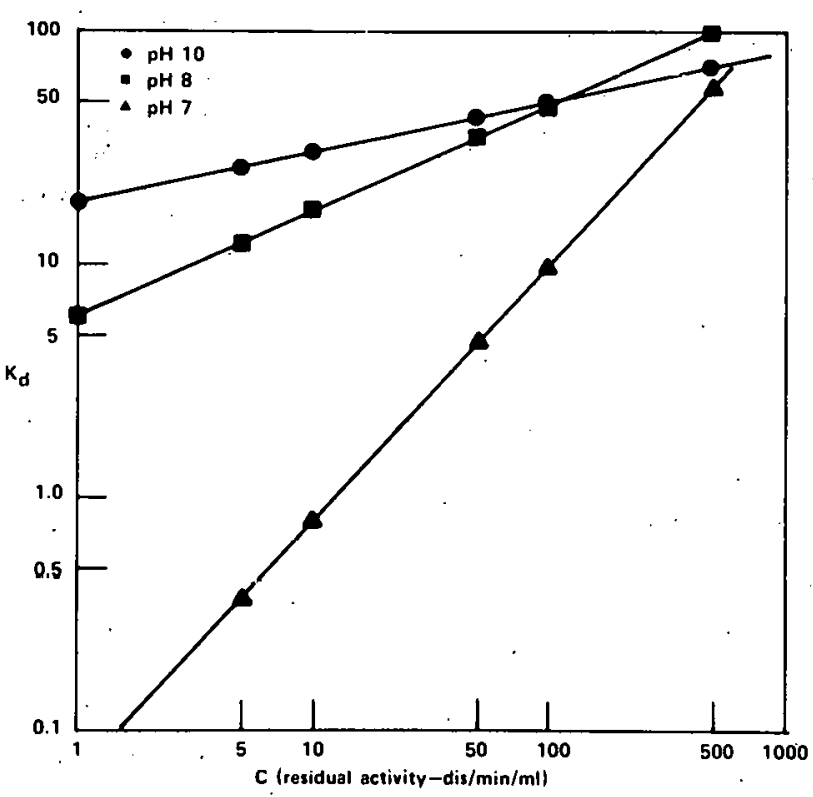

FIGURE 34 - Comparison of the distribution coefficient $\left(K_{\mathrm{d}}\right)$ with concentration (C) at various $p H$ values.

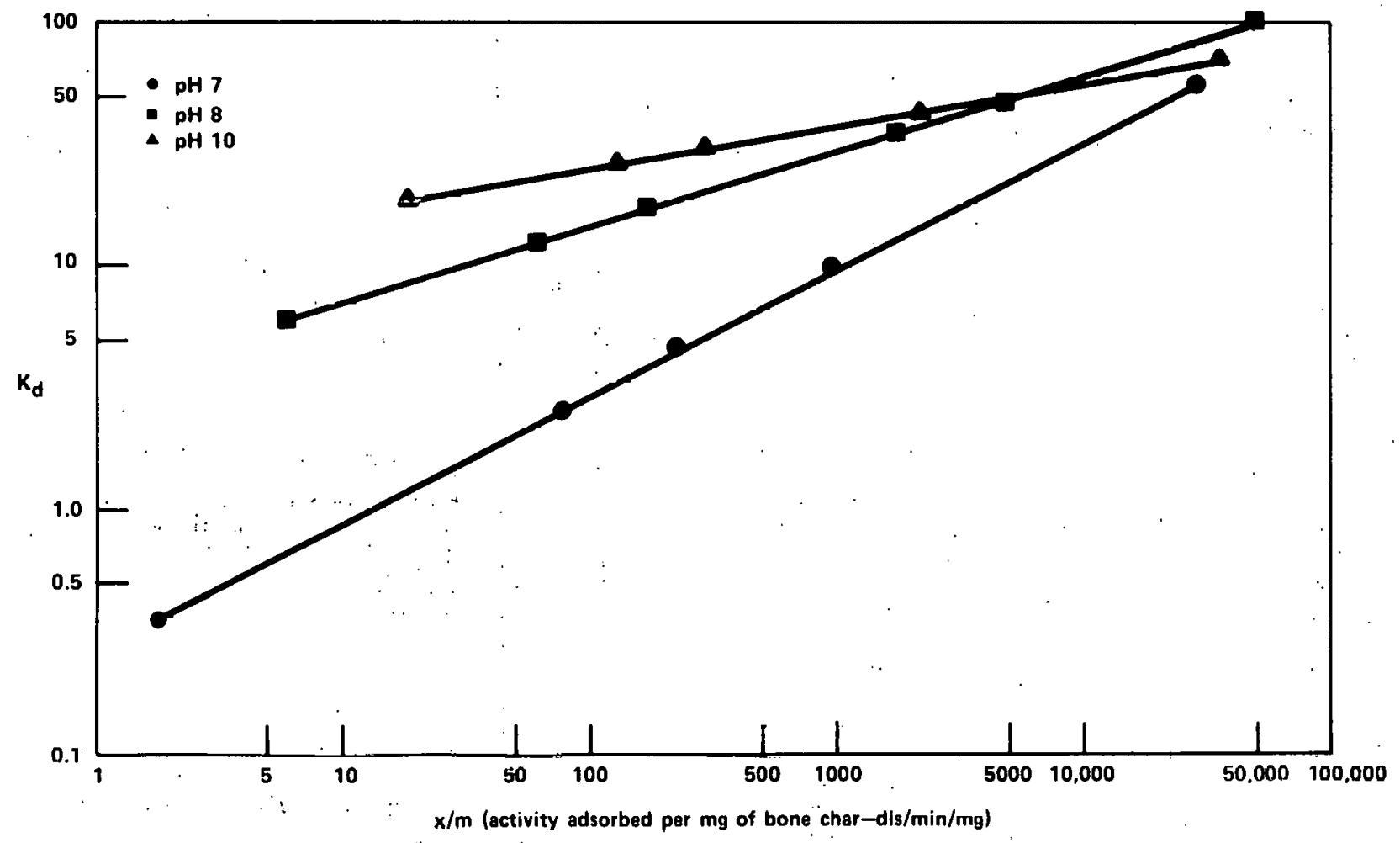

FIGURE 35 - Comparison öf the distribution coefficient ( $K_{\mathrm{d}}$ ) with loading of the sorbent $(x / m)$ at various $p \ddot{H}$ values. 


$$
\begin{array}{ll}
\text { (1) } \mathrm{UO}_{2}{ }^{2+} \\
\text { (2) }\left(\mathrm{UO}_{2}\right)_{2} & (\mathrm{OH})_{2}{ }^{2+} \text { (Dimer) } \\
\text { (3) }\left(\mathrm{UO}_{2}\right)_{3} & (\mathrm{OH})_{5}+\text { (Trimer) }
\end{array}
$$

As the $\mathrm{pH}$ of the solution is increased, the formation of dimeric and trimeric species occurs more readily. The mechanism of uranium removal by the bone char is thought to be chemisorption, so that at $\mathrm{pH}$ 10, where dimers and trimers exist, more uranium may be removed per reactive site on the surface of the bone char particles. Therefore, high $\mathrm{K}_{\mathrm{d}}$ values are apparent at $\mathrm{pH} 10$ and the change in $\mathrm{K}_{\mathrm{d}}$ with $C$ is not as drastic as at pH 7 . This is because the uranium is primarily in the trimeric form at $\mathrm{pH} 10$, whereas at $\mathrm{pH} 7$ it also exists as dimers and unassociated species. The distribution of uranium species at $\mathrm{pH} 7$ is more sensitive to total uranium concentration than at $\mathrm{pH}$ 10. At $\mathrm{pH} 7, \mathrm{~K}_{\mathrm{d}}$ values are quite low, compared to $\mathrm{pH} 10$, and $\mathrm{K}_{\mathrm{d}}$ changes very rapidly with $\mathrm{C}$, indicative of polymer formation.

The second possible adsorption mechanism is that of complex formation. Since the commercial bone char is relatively impure, a number of possible complexing. agents may be dissolved from the bone char. These include phosphate and carbonate ions, and many other species that may be derived from partially decomposed. animal matter... $K_{d}$ is defined as the ratio of uranium adsorbed by the bone char to the concentration of uranium in the aqueous phase

$$
\mathrm{K}_{\mathrm{d}}=\left(\mathrm{UO}_{2}^{2+}\right) \text { adsorbed/( }\left(\mathrm{UO}_{2}^{2+}\right) \text { liquid.. }
$$

If complexing agents are present, however,

$$
\mathrm{K}_{\mathrm{d}}=\text { sorbed uranium } /\left(\mathrm{UO}_{2}^{2}+\mathrm{U}^{*}\right)^{\star} \text {, }
$$

where $U^{*}$ is complexed uranium. Since the solubility of bone char decreases with increasing $\mathrm{pH}$, fewer complexing agents may be derived from the bone char at high $\mathrm{pH}$ values than at low $\mathrm{pH}$ values. Hence, the degree of complexation of the uranium decreases with increasing $\mathrm{pH}$. Since complexation of uranium interferes with the adsorption of uranium by bone char, $\mathrm{K}_{\mathrm{d}}$. values decrease with decreasing $\mathrm{pH}$.

\section{ADSORPTION OF PLUTONIUM BY BONE CHAR}

Experiments have been performed to determine the removal effectiveness of bone char (as determined by adsorption isotherms) for plutonium as a function of $\mathrm{pH}$. The $\mathrm{pH}$ values selected for study were $\mathrm{pH} 7 ; 8$ and 10 . 'The isotherms measured at these $\mathrm{pH}$ values are shown in Figures 36-41. The valence state of the plutonium used in these experiments was either hexavalent or tetravalent, as noted in the Figures. (The tetravalent oxidation state is the polymeric form of plutonium.) It can be seen from Figures 36-38 that at pH 10 the bone char has a relatively low capacity for plutonium(IV) at low concentrations ( $<10 \mathrm{dis} / \mathrm{min} / \mathrm{ml})$, whereas at $\mathrm{pH} 7$ the bone char has a relatively high capacity for tetravalent plutonium at high concentrations. However, at very high concentrations $(>100,000$ $\mathrm{dis} / \mathrm{min} / \mathrm{ml}$ ), bone char has a higher capacity for plutonium(IV) at $\mathrm{pH} 10$ than at $\mathrm{pH} 7$. At intermediate concentration levels $(1000-10,000 \mathrm{dis} / \mathrm{min} / \mathrm{ml})$, the bone char capacity for plutonium polymer adsorption is higher at pH 7 and $\mathrm{pH} 8$. Figure 39 shows another method of describing the adsorption of plutonium(IV) polymer by bone char. This figure was prepared from data collected from solutions of constant volume and bone char weight, but with varying amounts of initial plutonium radioactivity. Figure 39 is not comparable to other figures herein because it was taken from solutions buffered at pH 7.3, and because; the axes are not scaled in the same units. Nevertheless, Figure 39 indicates the same general adsorption characteristics as indicated by previous figures.

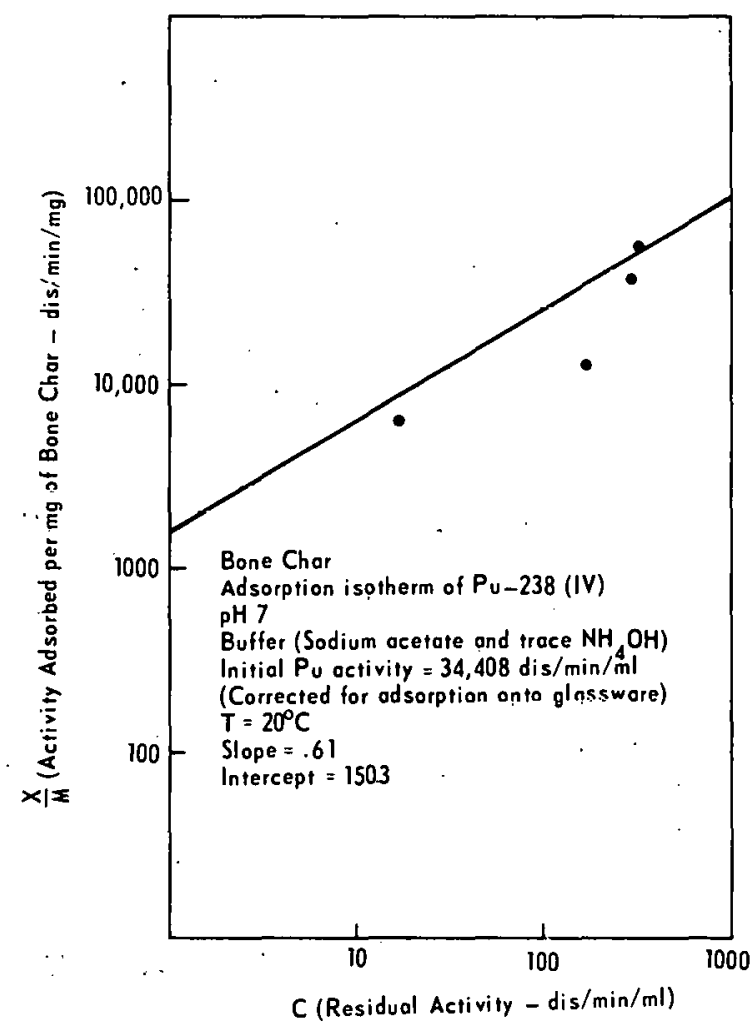

FIGURE 36 - Adsorption of plutonium(IV) polymer onto bone char at $p H 7$. 


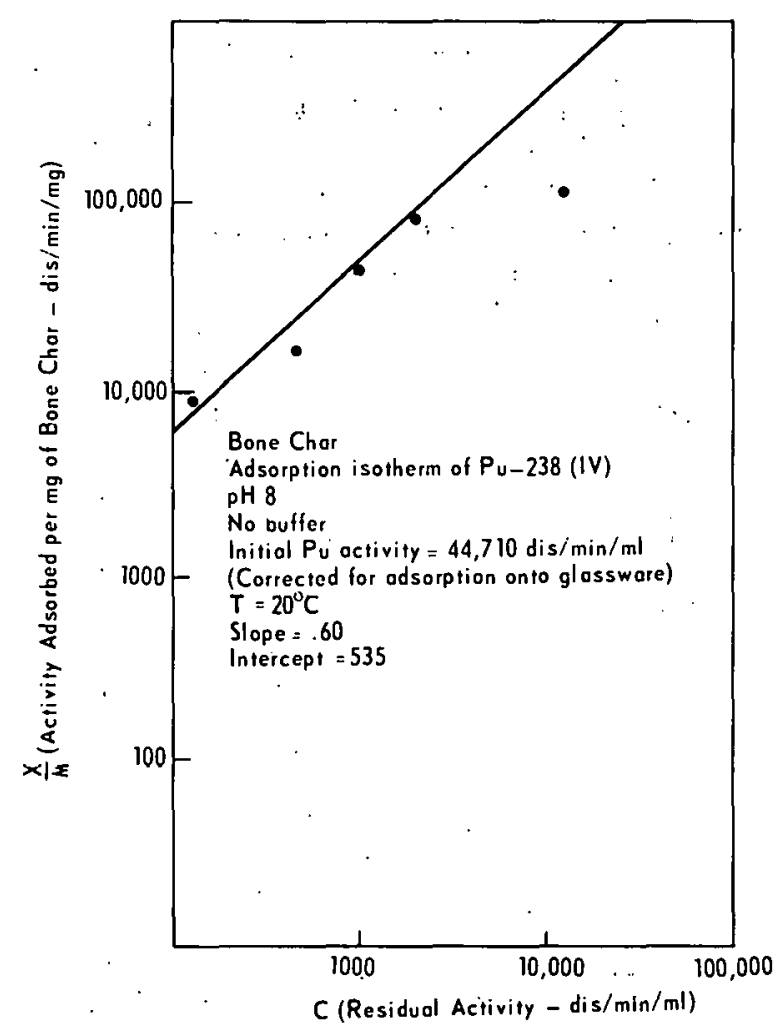

FIGÜRE $37^{-}$- Adsorption of plutonium(IV) onto bone char at $p H 8$.

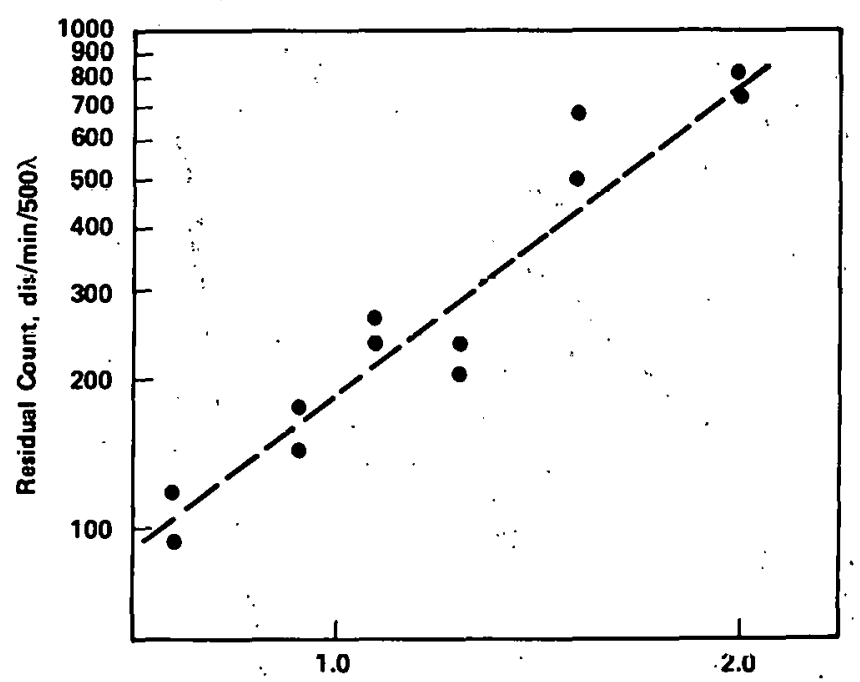

Log Initial Plutonium Concentration (Arbitrary Uńits - One Unit Initial Plutonium Concentration $=4568 \mathrm{dis} / \mathrm{min} / 500 \lambda$ I

FIGURE 39 - Approximate'polymer loading isotherm for $1 \mathrm{~g}$ bone char ( $\mathrm{pH} 7.3$, ethyleatdiamine hydrochlorido buffar).

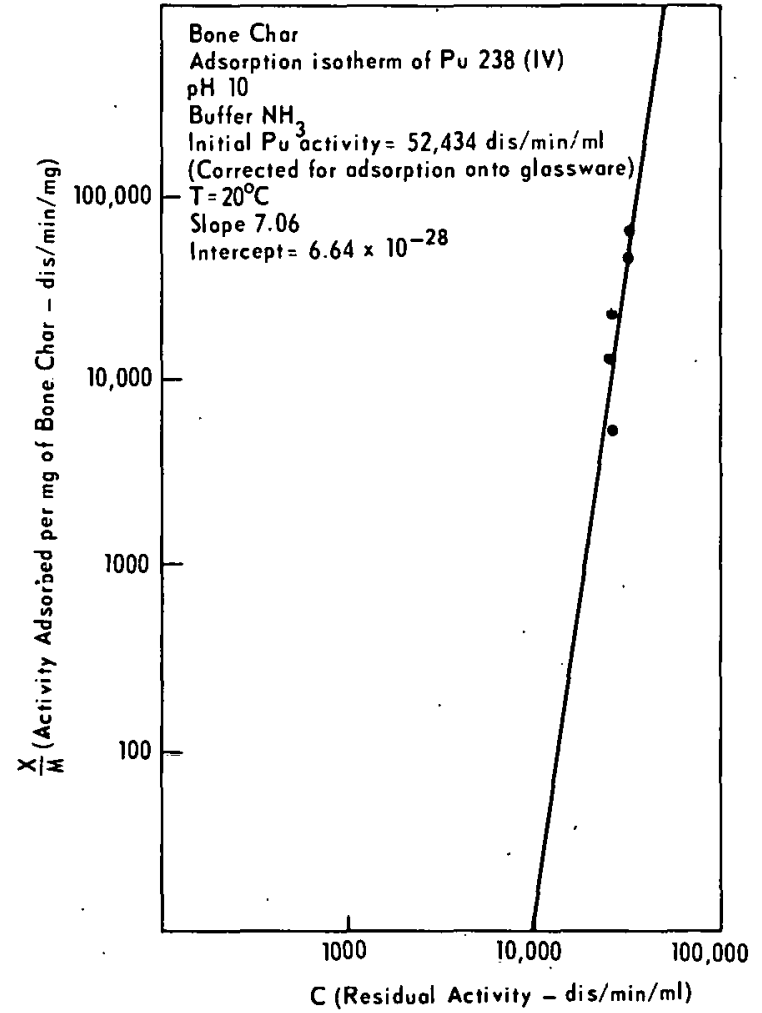

FIGURE 38 - Adsorption of plutonium(IV) onto bone char at $p H 10$.

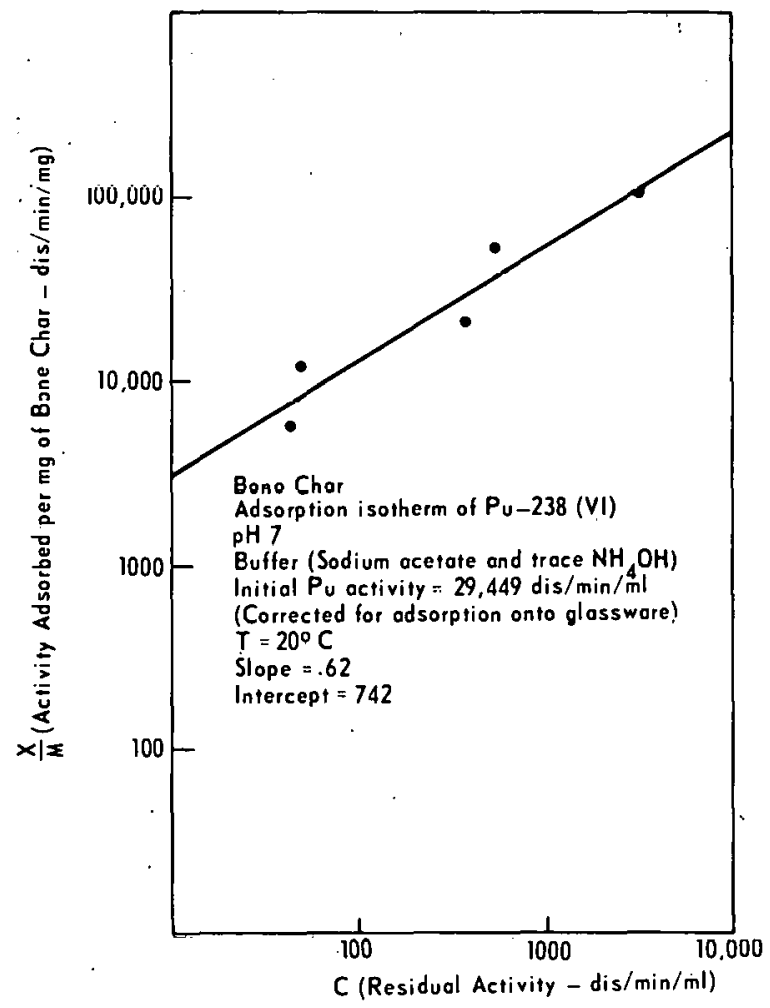

FIGURE 40 - Adsorption of plutonium(VI) onto bone char at pH 7 . 


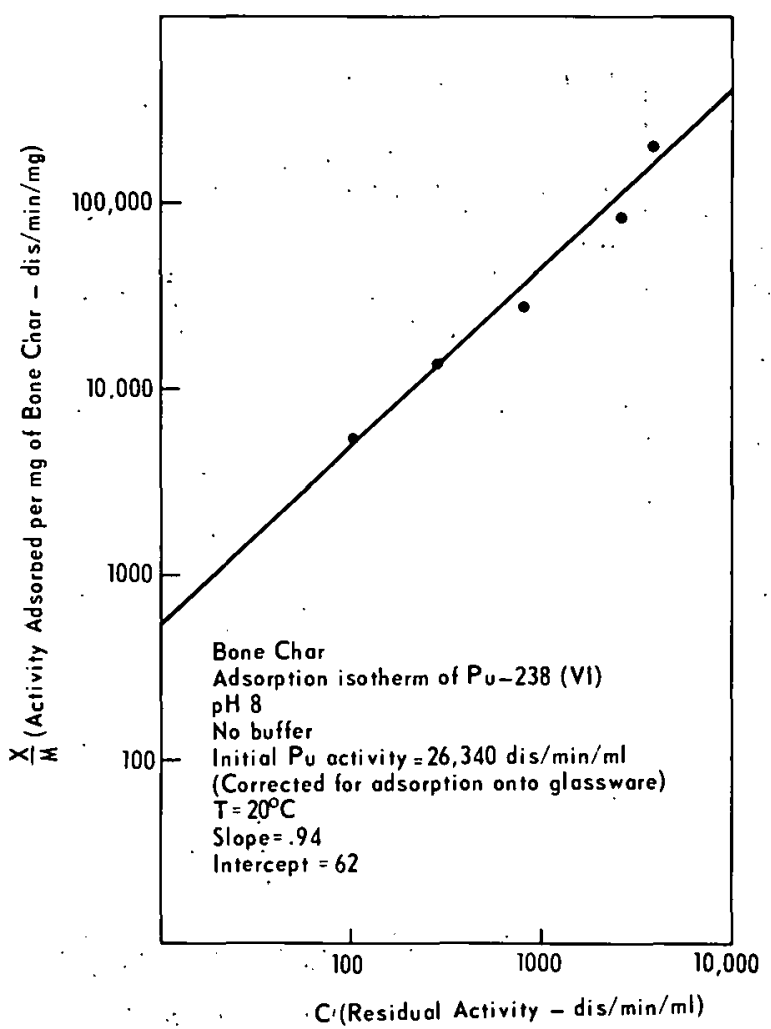

FIGURE 41 - Adsorption of plutonium(IV) onto bone char at pH 8 .

For adsorption of hexavalent plutonium (Figures 40-42), the $\mathrm{pH} 7$ isotherm shows that the bone char has a higher capacity at low concentrations of plutonium(VI). However, for both intermediate concentrations and high concentrations of hexavalent plutonium, the isotherm at $\mathrm{pH} 10$ indicates greater capacity of the bone char for plutonium adsorption at pH 10 .

Unless the concentration of the plutonium is specified, no definite conclusions about the adsorption mechanism at various $\mathrm{pH}$ values for various oxidation states of plutonium can be made. The fact that the intercepts and slopes of the adsorption isotherms change rapidly with changing pH (see Figures 43 and 44 ) causes the isotherms to intersect. Only if the plutonium concentration is specified can the best $\mathrm{pH}$ and mode of plutonium removal be determined from these isotherms.

By comparison of the adsorption of plutonium(IV) and plutonium(VI) at the same $\mathrm{pH}$ values (Figure 45), it may be seen that the isotherms. for $\mathrm{pH} 7$ and $\mathrm{pH} 10$ are almost parallel in the plutonium concentration range studied. Isotherms for plutonium(IV) and plutonium(VI) at $\mathrm{pH} 8$ are nearly coincident. At pH 8, therefore, the behavior of plutonium (IV) and

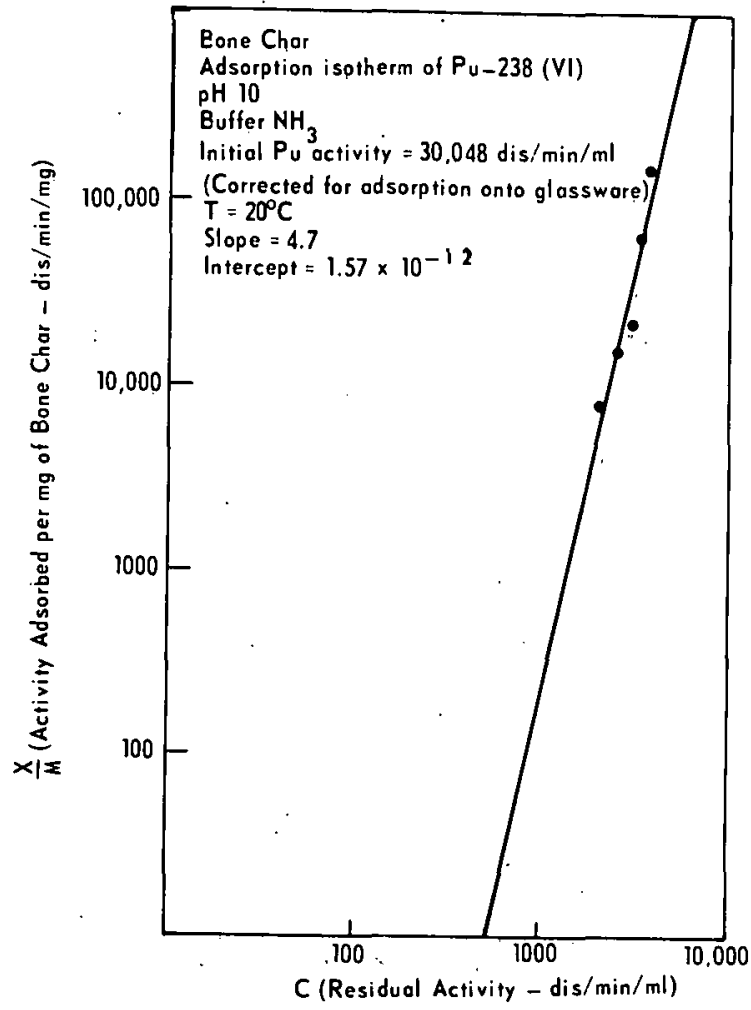

FIGURE 42 - Adsorption of plutonium(VI) onto bone char at pH 10 .

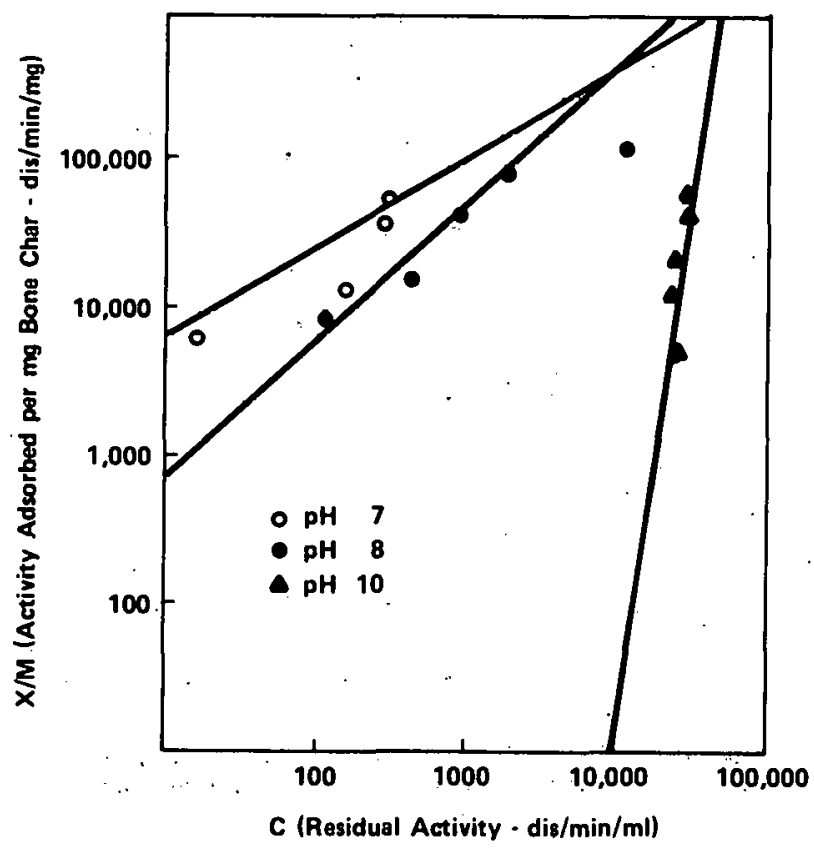

FIGURE 43 - Comparison of adsorption of plutonium(IV) onto bone char at various pH values. 


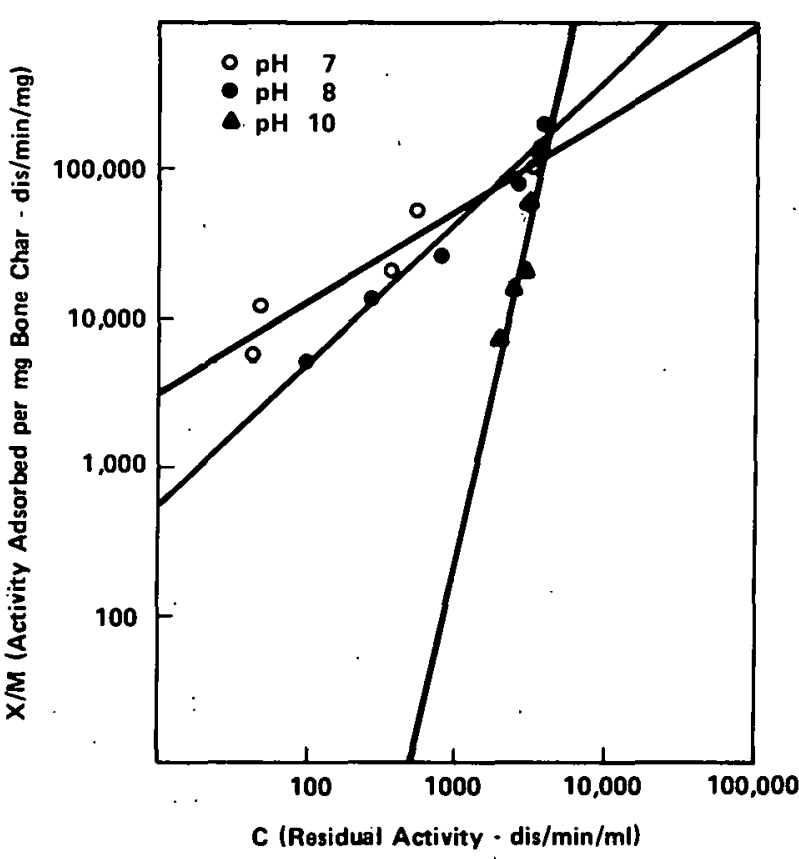

FIGURE 44 - Comparison of adsorption of plutonium(VI) onto bone char at various pH values.

plutonium(VI) toward bone char is quite similar. The data at $\mathrm{pH} 10$ indicate that for a given plutonium(VI) concentration the bone char has a much higher capacity for plutonium(IV) than for plutonium(VI). This change in affinity for the two plutonium valence states occurs around pH 8 .

\section{SUMMARY OF ISOTHERM EXPERIMENTS}

These experiments were performed to determine the $\mathrm{pH}$ dependence of the effectiveness of removal of uranium and plutonium from aqueous solutions by commercial bone char. Since bone char tends to be slightly soluble at $\mathrm{pH}$ values below $\mathrm{pH} 7$, the $\mathrm{pH}$ values selected for study were $\mathrm{pH} 10, \mathrm{pH} 8$, and $\mathrm{pH} 7$. The behavior of uranium and plutonium adsorption by bone char can be modeled using the freundlich equation. A summary of the results of the various adsorption isotherms is shown in Table 5. This table indicates that there is little similarity in the. adsorption behavior of uranium and plutonium. In all cases, the slopes of the uranium adsorption isotherms at various $\mathrm{pH}$ values were greater than unity. The slopes of plutonium adsorption isotherms

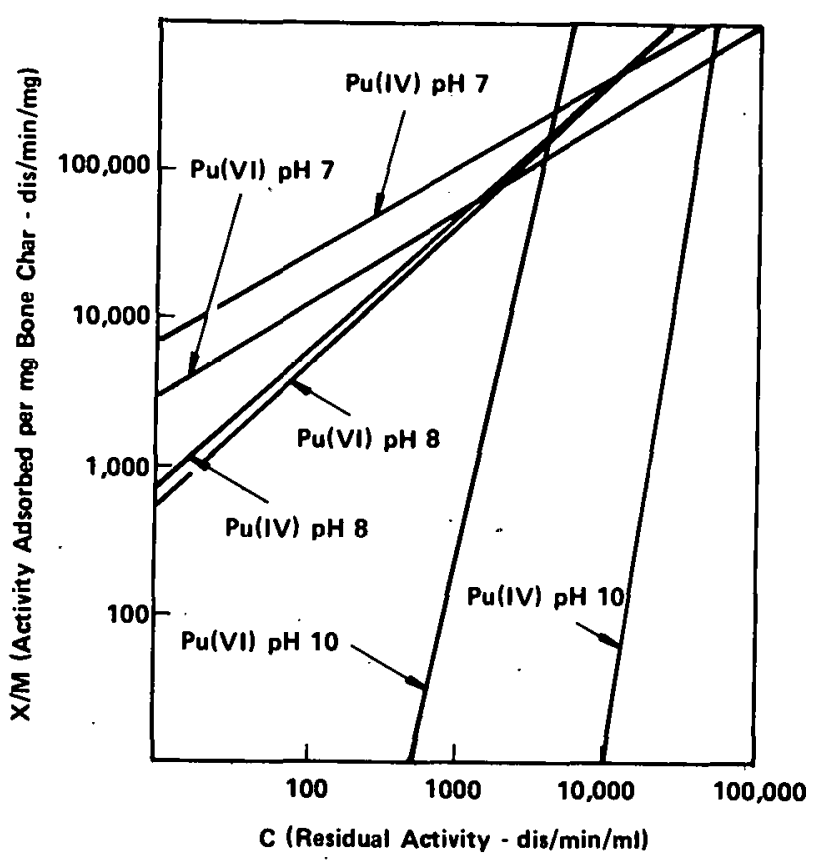

FIGURE 45 - Comparison of plutonium(IV) with plutonium(VI) onto bone char at various $p H$ values.

at $\mathrm{pH} 7$ and $\mathrm{pH} 8$ were less than unity, while at $\mathrm{pH} 10$ the slope of the adsorption isotherm was greater than unity for both plutonium valence states.

one reason why comparisons between the data relating to uranium or plutonium cannot easily be made is that the concentration ranges of these two elements differed significantly. Since similar radioactivity levels were used in this study, the concentrations of uranium and plutonium varied by a factor of $1.8 \times 10^{3}$, due to the difference in the specific activities of uranium-234 and plutonium238. This large difference in the concentrations of the uranium and plutonium used in these studies makes comparisons difficult.

A second reason why comparisons between uranium and plutonium are difficult is that, in the case of plutonium, a precipitate of unknown origin was occasionally found to form in the experimental solutions, suggesting further polymerization or adsorption of the plutonium on the precipitate. This caused large deviations from the Freundlich isotherm model of adsorption. This is shown by examination 
Table 5

RESULTS OF BONE CHAR ADSORPTION ISOTHERMS

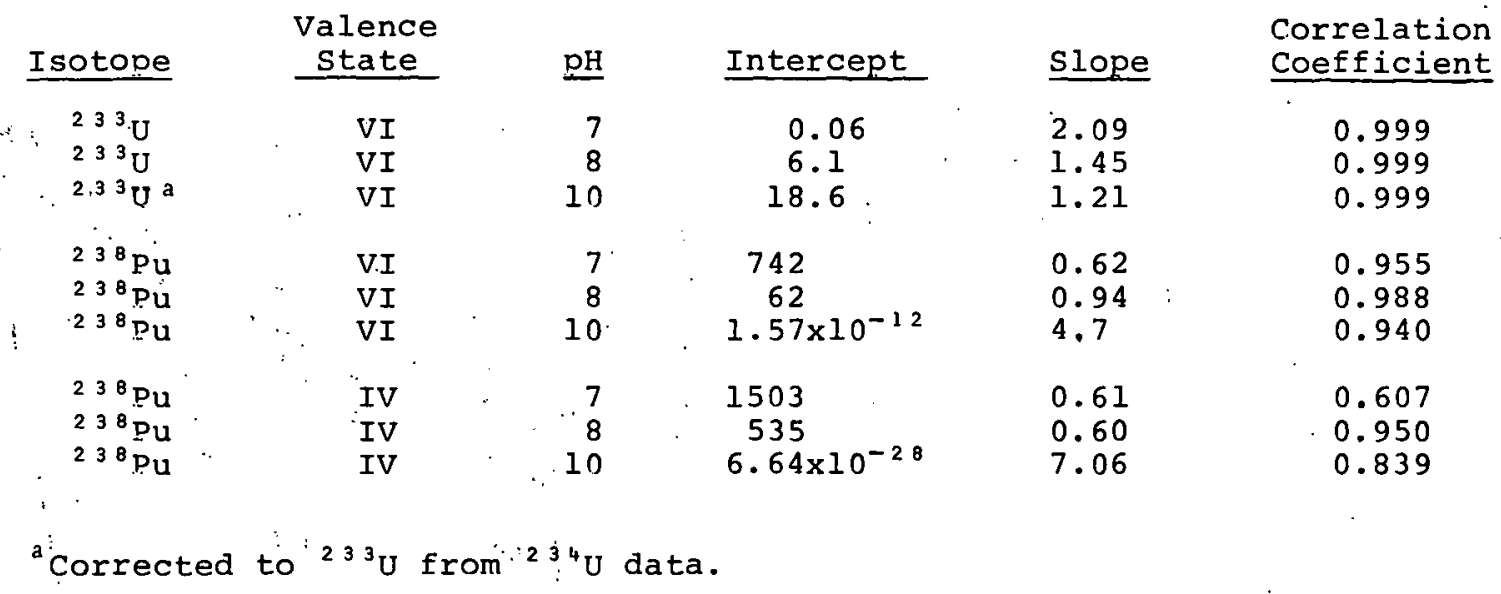

of correlation coefficients. A correlation coefficient is a measure of how well a straight line fits, the observed adsorption data. The correlation coefficient is usually denoted by the letter " $r$ ", and is calculated with the following equation:

$$
r=\frac{\left[\left(\sum_{i=1}^{N} \dot{x}_{i} y_{i}\right) / N\right]-\bar{x} \bar{y}}{\sigma_{x} \sigma_{y}}
$$

where $\sigma_{y}^{2}=$ variance of the $y$ coordinate values

$$
=\left[\left(\sum_{i=1}^{N} y_{i}^{2}\right) / N\right]-\bar{y}^{2}
$$

$\sigma_{x}^{2}=$ variance of the $x$ coordinate values

$$
=\left[\left(\sum_{i=1}^{N} x_{i}^{2}\right) / N\right]-\bar{x}^{2}
$$

$\overline{\mathrm{X}} \cdot=$ average $\mathrm{x}$ coordinate value

$$
=\left(\sum_{i=1}^{N} x_{i}^{2}\right) / N
$$

$\bar{y}=$ average $y$ coordinate value

$$
=\left(\sum_{i=1}^{N} y_{i}^{2}\right) / N
$$

$\mathrm{N}=$ Number of data values
When " $r$ " is \pm 1.0 , correlation is said to be exact. When $r=0$, the experimental variables are said to be uncorrelated by a linear expression. Representation of uranium adsorption data is well accomplished by a linear model because all " $r$ " values for uranium adsorption data exceeded 0.999, and this represents an almost perfect fit to a straight line model. Plutonium(VI) adsorption is not so well represented by a straight line, as the values for "r" lay between 0.94 and 0.98 . Adsorption data for plutonium(IV) also did not fit the straight line model, as indicated by still lower " $r$ " values. Either the adsorption behavior of plutonium(IV) as a function of plutonium concentration at a given $\mathrm{pH}$ is not linear (as plotted by Freundlich isotherms expressed in logarithms), or scatter in data was caused by formation of longchained polymers. of these two explanations, the latter seems more likely. 


\section{References}

1. H. W. Kirby", "Removal of Radioisotopes from Waste Solutions," U. S. Patent $3,764,553$ (October 9, 1973).

2. D. E. Blane and E. L. Murphy, Mound Laboratory Activities on the Removal of Radionuclides from Wastewater Using Bone Char, MLM-2244 (September 15, 1975), 17 pp.

3. D. E. Blane and E. L. "Murphy, Mound Laboratory Activities on the Removal of Plutonium and Uranium from Wastewater Using Bone Char, MLM-237l (September 30 , 1976), $10 \mathrm{pp}$.

4. G. J. Levinskas and W. F. Neuman, J. Phys. Chem., 59:2, 164-168 (February 1955).

5. H. M. Rootare, V. R. Déitz, and F. G. Carpenter, J. Colloid Sci., 17., 179-206 (1962).

6. V. K. LaMer, J. Phys. Chem., 66:6, 973-978 (June 1962).

7. J. S. Clark, Can. J. Chem., 33:11, 1696-1700 (November 1955).

8. E. C. Moreno, T. M. Gregory, and W. E. Brown, J. Res. Nat. Bur. Stand., Sec. A, 72:6, 773-782 (1968).

9. D. R. Wier, S. H. Chien, and C. A. Black, Soil Sci., 111:2, 107-112 (1971).

10. M.,D. Francis, Ann. N..Y.Acad. Sci., 131:2, 694-712 (1965).

11. K. N. Amin, Solubility of Hydroxyapatite and Its Inhibition by Phosphate, Ph.D. Dissertation, University of Michigan, 1971. UUniversity Microfilms, Ann Arbor, Michigan, No. 72-4814).

12. S. O. Zimmerman, Bull. Math. Biophys., 28:3, 433-441 (1966).

13. D. R. Wier, Solubility of Hydroxylapatite and Some Phosphate Rocks, Ph.D. Dissertation, Iowa state University, 1968. (University Microfilms, Ann Arbor, Michigan, No. 69-4289).

14. J. B. Best and J. Z. Hearon in Mineral Metabolism, Vol. lA, C. L. Comar and Felix Bronner (Editors), Academic Press, New York, 1960, pp. 12-60.

15. W. L. Lindsay and E. C. Moreno, Soil Sci. Soc. Am., Proc., 24:3, 177-182 (1960).

16. T. G. Chaverri. and C. A. Black, Iowa State J. Sci., 4l:1. 77-95 (1966).

17. N. S. Chickerur, R. P. Singh, and T. S. B. Narasaraju, Naturwissenschaften, 56:5, 282-283(1969).

18. B. H. G. Brady, D. H. Napper, and B. M. Smythe, Nature, 212:5057, 77-78 10ctober $1,1966)$.

19. A. Perloff and A. S. Posner in Inorganic. Syntheses, Vol. VI, Eugene G. Rochow (Euitur), McGraw-Hill, New York, 1960, pp. 16-18.

20. E. Hayek and $H$. Newesely in Inorganic Syntheses, Vol. VII, Jacob Kleinberg (Editor), McGraw-Hill, New York, $1963, \frac{19}{\mathrm{p} p} 6 \overline{3}-65$.

21. R. W. Mooney and M. A. Aia, Chem. Rev., 61, 433-462 (1961).

22. J. K. Jacques, J. Chem. Soc., Part III, 3820-3822 (July 1963).

23. C. Y. C. Pak and F. C. Bartter, Biochimica Et Biophys. Acta, 141:2, 401-409 (1967). 
24. C. Y. C. Pak and F. C. Bartter, Biochimica et Biophys. Acta, 141:2, 410-420 (1967).

25. W. V. Loebenstein, J. Colloid Interface Sci., 36:2, 234-246 (1971).

26. M. M. Golutvina, L. S. Semochkina, N. N. Kononykina, and V. M. Ezhova, Radiokhimiya, 15:4, 636-639.(1973).

27. W. F. Schmid, M. A. Aia, and R. W. Mooney, J. Inorg. Nucl. Chem., 28:5, 1325-1328 (1966).

28. W. V. Loebenstein, J. Res. Nat. Bur. Stand., Sect. A, 66:6, 503-515 (1962).

29. M. C. Bennett and" J. C: Abram, J. Colioid Interface Sci., 23:4, 521-529 (1967).

30. Y. V. Egorov in Coprecipitation and. Adsorption of: Radioactive Elements, V. M. Vdovenko (Editor), Israel Program for Scientific Translations, Jerușalem, 1967, p. 130 .

31. C. E. Mellish, J. A. Payne; and G. Worrall, Radiochimica Acta, 2:4, 204-210 (1964).

32. J. B. Andelman and T. C. Rozzeli in Radionuclides in the Environment, S. C. Freiling (Editor), ACS Advances in Chemistry Series No. 93, American Chemical Society, Washington, D. C., 1970, pp. 118-137.

33. F." Kèpak, Chem. Rej., 71:4, 357-369 (1971).

34. G. L. Silver, Radiochem. Radioanal..Lett., 7:1, 1-5 (1971).

35. G. L. Silver, Plutonium Disproportionation Reactions: Some Unresolved Problems, MLM-1807 (May 10, 197I), 56 pp. 


\section{Distribution}

\section{EXTERNAL}

TIC, UC-10 (112)

R. R. Fredlund, ALO

R. Y, LOWrey, ERDA/ALO

R. A. Wolfe, ERDA/DNFCP

W. J. Haubach, ERDA/DPR

F. D. Stevenson, ERDA/DPR

C. P. Sutter/R. N. Diebel, ARHCO

Technical Report Library, St. Louis

Center for Atomic Energy Documentation (ZAED)

Karlsruhe, Germany

Dr. Peter J. Dyne, Atomic Energy of Canada Ltd.

R. K. Flitcraft, MRC

U. A. Chacon, DnO for:

B. C. Blanke, ERDA/DAO

\section{Consultants}

W. E. Moddeman

Research Institute University of Dayton

Dayton, Ohio 45406
Dr. D. White

Department of Chemistry. University of Pennsylvania philadelphia, Pennsylvania

Dr. R. N. Zare

Department of Chemistry

Columbia University

New York, New York 10025

INTERNAI
A. G. Barnett
D. E. Blane
W. T. Cave
D. A. Edling
T. C. Elswick
K. V. Gilbert
W. R. Harris
W. R. Herald
C. W. Huntington
E. W. Johnson
L. V. Jones
D. P. Kelly
J. W. Koenst (3)
B. R. Kokenge
D. F. Luthy
J. R. McClain
G. L. Silver (3)
F. A. Traino
H. I. Turner
R. E. Vallee

Library (15)

Publications (15) 